\title{
El verbo que dio nombre a la ontología. Una aproximación lingüística a la metafísica clásica
}

\author{
Ricardo Alcocer Urueta $^{1}$
}

Recibido: 24 de Julio de 2019 / Aceptado: 30 de Septiembre de 2019

Resumen. En este artículo propongo una aproximación lingüística a la ontología clásica y sugiero que el concepto griego de 'ser' fue determinado por las propiedades del verbo eỉuí. En primer lugar, caracterizo esta palabra como un verbo estativo de soporte, léxicamente débil y con aspecto imperfectivo. En segundo lugar, asocio los rasgos de eỉuí con la expresión polisémica de lo ente, así como también con la oposición filosófica entre la permanencia del ser y la transitoriedad del devenir.

Palabras clave: ontología; ser; devenir; predicado no verbal; aspecto verbal; Parménides; Platón; Aristóteles.

\section{[en] The Verb that Gave Name to Ontology. A Linguistic Approach to Classical Metaphysics}

Abstract. In this article I put forward a linguistic approach to classical ontology and suggest that the Greek concept of 'being' was determined by the properties of the verb sijuí. In the first place, I characterize this word as a lexically weak, supportive and stative verb with imperfective aspect. In the second place, I associate the features of eilui with the polysemic expression of being as well as with the philosophical opposition between the permanence of being and the transience of becoming.

Keywords: ontology; being; becoming; non-verbal predicate; verbal aspect; Parmenides; Plato; Aristotle.

Sumario. 1. Introducción. 2. El verbo eỉuí como soporte de categorías gramaticales. 3. La información aportada por cỉ í a las oraciones. 4. Bases para la interpretación lingüística de la ontología griega.

Cómo citar: Alcocer Urueta, R. (2020) El verbo que dio nombre a la ontología. Una aproximación lingüística a la metafísica clásica, en Cuadernos de Filología Clásica. Estudios griegos e indoeuropeos 30, 23-49.

$1 \quad$ Instituto de Filosofía, Universidad de Viena

ricardo.alcocer.urueta@gmail.com

Ich danke Prof. Dr. George Karamanolis, Vorstand des Instituts für Philosophie der Universität Wien, für seine freundliche Aufnahme an dieser Institution. 


\section{Introducción}

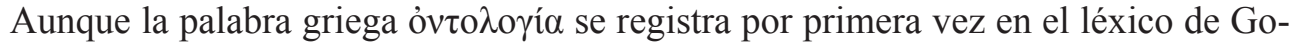

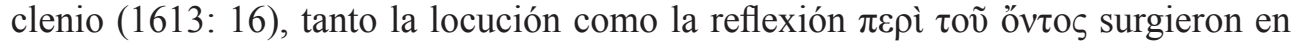
la antigua Grecia por razones concretas. Parménides juzgaba que cualquier objeto

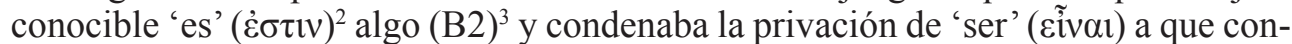
ducían los relatos tradicionales sobre la configuración cósmica (B4, B8.15-18). En efecto, 'ser' le correspondía a todo por igual, así que no tenía sentido explicar las diferencias a partir de variaciones o interrupciones de $\operatorname{ser}\left(\right.$ B8.22-25) ${ }^{4}$. Sin embargo, la doctrina parmenídea fue tergiversada al poco tiempo por dialécticos que invalidaban toda referencia a la falsedad y la apariencia, pretextando que lo falso y lo aparente no son realmente ${ }^{5}$. Por ello, Platón se vio en la necesidad de zanjar la cuestión y no solo determinó varios modos de participar de lo 'ente' (őv), es decir, del 'ser' y de la 'entidad' (ov̉oía) (Prm. 142b1-157b5), sino que también definió la 'entidad' de

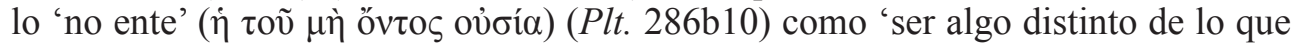
otras cosas son' (Sph. 257b1-264b8). Así, con la justificación de la variedad de lo 'ente' y lo 'no ente', quedaron sentadas las bases de la ontología propiamente dicha, pues Aristóteles se convenció en algún momento ${ }^{6}$ de que todos los modos de 'ser' y 'no ser' dependen de un mismo principio (Metaph. IV 2 1003a33-b16) y propuso estudiar el núcleo de semejante organización, a saber, la 'entidad' (Metaph. VII 1 1028b2-7), que distaba ya de la 'entidad' platónica.

Fuera de las discrepancias que pueda provocar el recuento anterior, siempre ha llamado la atención que los filósofos griegos designaran un objeto de estudio con las expresiones (de)verbales que acabamos de leer. Ya en la Edad Antigua, Séneca (Ep. 58.6-7) lamentaba la estrechez (angustia) de la lengua latina, que carecía de traducciones para dichos términos. Los romanos tuvieron que generar un neologismo aparentemente disonante como essentia para traducir el sustantivo ov̉oía y Séneca creía usar una categoría gramatical distinta de la original cuando convertía el participio ỏv al latín quod est, pues se veía forzado a «poner un verbo en lugar de un nombre» (verbum pro vocabulo ponere). Probablemente, como la forma nominal őv comparte propiedades sintácticas con las formas personales de cỉuí, el cordobés se quejaba en el fondo de que los romanos distinguieran con mayor rigidez que los griegos entre formas finitas e infinitas del verbo. Por otra parte, y ya más cerca de nosotros, John Stuart Mill (1981 [1843]: 78-80) y Bertrand Russell (1920 [1919]: 172; 2000 [1945]: 168) se concentraron en las diferencias semánticas de las oraciones con verbos como cíní y argumentaron que öv y oủoía, entre otras nominalizaciones, confunden esos papeles.

Ahora bien, no cabe duda de que los términos Eĩval, öv y oủoía tienen implicaciones semánticas y gramaticales singulares. Por lo mismo, antes de juzgar sobre su pertinencia o impertinencia teórica, deberíamos investigar las propiedades lingüísticas de tales expresiones en cuanto formas de presente de la cópula griega por antonomasia ${ }^{7}$. En consonancia con ello, este trabajo asocia las peculiaridades lingüís-

\footnotetext{
Véase n. 21.

Omito la indicación DK 28 cada vez que aludo a los fragmentos B de Parménides (Diels \& Kranz 1960: 1, 227 ss.).

Compárese con DK 12 B 1 y DK 13 B 1-3. Sobre la reformulación onto-lógica del monismo materialista en

Parménides, véase Finkelberg (1988).

Cf. Euthd. 284c2-6, 286b8-e7 y 300e3-301b4; Sph. 236d9 ss.; Metaph. V 29 1024b32-34.

Compárese EE I 8 1217b25-35 con Metaph IV 1-2.

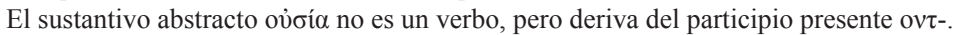


ticas de eỉuí con la metafísica clásica: en primer lugar, presenta dicho verbo como una palabra que desempeña un papel eminentemente funcional en las oraciones; en

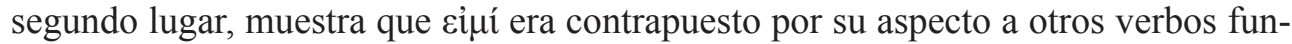
cionalmente similares; en tercer lugar, relaciona lo anterior con las ontologías de Parménides, Platón y Aristóteles.

\section{El verbo sỉuí como soporte de categorías gramaticales}

Analizable como intransitivo, copulativo y auxiliar, gìú se construye de muchas maneras $^{8}$. En oraciones aparentemente predicativas', se usa para expresar 'vigencia' (vg. Ar. Nu. 902-906), 'situación' (vg. Il. XIII 32), 'correspondencia' ${ }^{10}$ (vg. Il. VI 413), 'existencia' (vg. DK 74 B 4), 'verdad' (vg. Hdt. V 50.7) o 'posibilidad', entre otras modalidades (vg. Il. XXI 193). De ahí que pueda traducirse como 'estar vigente, estar vivo, subsistir' (vg. Od. XV 433); 'durar, perdurar, permanecer, transcurrir' (vg. Il. XIX 157); 'estar, hallarse, encontrarse' (vg. Od. XII 80); 'estar presente' (vg. Il. VII 73); 'existir, estar o quedar en existencia' (vg. Il. XXI 103); 'tener lugar, ser el caso' (vg. Il. VIII 373); 'ser verdad' (vg. Hdt. V 50.7); 'ser posible, ser apropiado' (vg. Il. XXI 193). En cambio, en calidad de verbo copulativo o auxiliar, siuí da a conocer sobre todo información gramatical, ya que el núcleo semántico de sus predicados reside en categorías léxicas con valor verbal, adverbial, adjetival, nominal (con o sin determinantes, declinadas o no) o incluso en sintagmas preposicionales ( $\mathrm{vg}$. Il. I 63). En estos casos, cỉuí vincula sujetos y atributos para caracterizar (vg. Aristot. Int. 18a23), subsumir (vg. Pl. Sph. 222b7), adjudicar (vg. Hdt. III 117.3), equiparar (vg. Hdt. III 108.15), o bien interactúa con formas no finitas del verbo en la construcción de predicados complejos o perífrasis verbales ( $v g$. Th. I 38.4.2). Además, las formas no finitas de eỉuí reproducen lo anterior: por ejemplo, sus participios se construyen con atributo (vg. X. An. I 1.11.2), denotan 'vida' o 'vigor' (vg. Il. XXII 384), se comportan como verbos de presentación ( $v g$. Th. IV 103.5.4), expresan modalidad ( $v g$. DK 68 B 174) o realidad efectiva ( $v g$. Hdt. V 50.7).

Evidentemente, la dicotomía entre predicados nominales y verbales impide explicar los ejemplos anteriores de manera unificada. Sin embargo, es posible que zì $\mu$ í cumpla una función de apoyo en todas sus oraciones, es decir, que aporte la información gramatical que no puede ser expresada por los elementos no verbales del predicado en cada caso. Así pues, a continuación veremos que las construcciones existenciales y auxiliares con zỉ pí pueden ser reducidas a estructuras copulativas o locativas y que incluso las estructuras locativas pueden ser entendidas como oraciones de predicado no verbal.

En las construcciones existenciales como «Todavía quedan jaguares en Calakmul», el verbo antecede a un sujeto indefinido, a diferencia de lo que sucede en las oraciones locativas y copulativas normales (Jespersen 1924: 154-156). Pese a ello, las estructuras existenciales han sido explicadas sincrónica y diacrónicamente

Este párrafo depende en buena medida de Kahn (2003).

Los autores logicistas suelen rechazar la naturaleza "predicativa" de las oraciones existenciales y ecuativas porque estas no asignan "predicados". Gramaticalmente, empero, no hay oraciones sin predicado (verbal o no verbal), así que reservo el término 'predicativo' para los verbos que no se construyen con atributo.

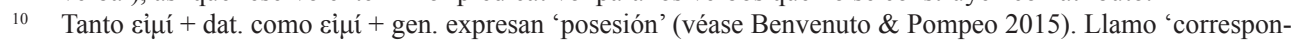
dencia' a la primera relación y 'propiedad' a la segunda. 
como locativas $^{11}$. Después de todo, los verbos usados en ellas suelen ser estativos (vg. avoir) e ir acompañados de elementos pronominales de naturaleza deíctica o incluso locativa ( $\mathrm{vg}$. there); piénsese en la semivocal [i] de la forma impersonal 'hay', que es «una variante enclítica del adverbio demostrativo y ('allí')» (NGLE 4.13b). Sin embargo, estas construcciones también han sido interpretadas como copulativas $^{12}$. En tal caso, el elemento pronominal es analizado como una partícula expletiva que remite catafóricamente al sujeto o al predicado de una cláusula reducida, es decir, de una cláusula que no expresa tiempo gramatical por sí misma. Por ejemplo, Moro (1997: 94-130; 2017: 171-192) ha propuesto que estas construcciones son oraciones copulativas inversas que implican varias operaciones sintácticas. A partir de la fractura de un sintagma determinante ( $v g$. a/one prime number between 6 and 8), se obtendría una oración de predicado nominal (vg. prime number between 6 and $8[i s] \underline{\text { one }}$ ), pero el predicado de la cláusula sería realizado mediante un elemento pronominal en posición preverbal ( $\mathrm{vg}$. there is one/a prime number between 6 and 8).

Las construcciones existenciales griegas pueden ser analizadas de ambas maneras. Por un lado, cỉuí es un verbo estativo que, independientemente de su posición en la oración, puede expresar la permanencia de un sujeto indefinido en determinadas condiciones ${ }^{13}$. De ahí que los complementos circunstanciales oscurezcan la diferen-

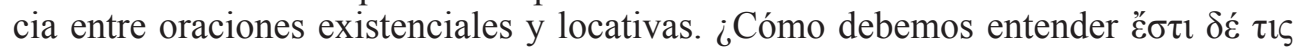

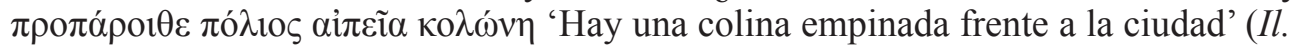

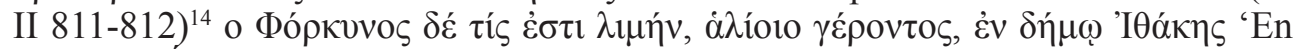
el país de Itaca se encuentra un puerto [consagrado] a Forcis, el viejo del mar' (Od. XIII 96-97)? ¿Se trata de oraciones locativas, existenciales o ambas? Por otro lado, es probable que cíní tenga orígenes deícticos ${ }^{15}$, y eso permite suponer que dicho verbo, habitualmente antepuesto al sujeto en las construcciones existenciales ( $v g$.

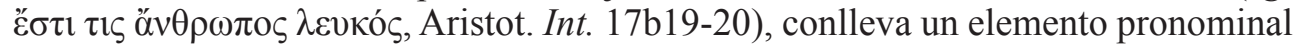
que remite a uno de los elementos no verbales de la cláusula reducida, bien al sujeto

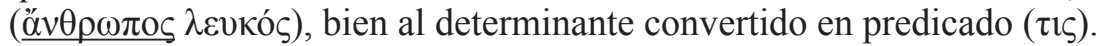

También algunas construcciones auxiliares con cỉ í tienen rasgos en común con las oraciones copulativas. Si una cópula tiene la función de presentar la información gramatical necesaria que no puede ser codificada por los elementos no verbales del predicado $^{16}$, entonces los verbos auxiliares como eỉní pueden ser analizados bajo el mismo paradigma, ya que expresan esa información en predicados constituidos por elementos léxicos con morfología nominal en cierta medida. De hecho, la frontera entre atributo y verbo auxiliado resulta especialmente borrosa cuando se trata

\footnotetext{
Véase Lyons (1967; 1968: 390), Freeze (1992) y Koch (2012).

Véase Hazout (2004).

13 Kahn (2003: xxiv-xxvii) sostiene que las construcciones existenciales sin complementos locativos o nominales, es decir, sin predicados secundarios de naturaleza adjetiva o preposicional, suponen la misma estructura, solo que no especifican las restricciones del valor de la variable representada por el sujeto indefinido.

14 Todas las traducciones al español son mías.

15 De acuerdo con Shields (1978; 1992: 53-56; 1997), el verbo atemático *hésmi combina la partícula deíctica *escon el sufijo - $i$, alusivo al aquí y al ahora. Sobre esto último, véase Szemerényi (1990: 357) y Back (1991: 282).

16 La llamada dummy hypothesis ha sido defendida por Meillet (1906), Benveniste (1966) y Lyons (1968: 322-323), entre otros. Según Stassen (1997: 65-67), esa hipótesis generaliza la naturaleza verbal de la cópula indoeuropea y asume que el presente y la tercera persona son las variedades no marcadas de sus respectivas categorías gramaticales en todas las lenguas. Ese posible sesgo no invalida mi argumento, ya que el griego antiguo es una lengua indoeuropea que admite la supresión de la cópula en presente y tercera persona.
} 
de participios, cuya morfología es ampliamente concordable con la del sujeto. Eso resulta evidente cuando las formas participiales pueden aparecer en posición atributiva sin variaciones: the students were invited $>$ the invited students; some children were crying > the crying children (Dik 1987: 56). Por consiguiente, no es raro que los griegos no distinguieran sintácticamente entre adjetivos y verbos $(\dot{\rho} \eta \dot{\eta} \mu \tau \alpha \alpha)^{17}$. Es verdad que los adjetivos se parecen morfológicamente a los sustantivos, pero se combinan más bien como los verbos (Bhat 1994: 165, 189), pues, para decirlo con Aristóteles (Int. 16b6-10), ambas clases de palabras significan cosas que se dicen de

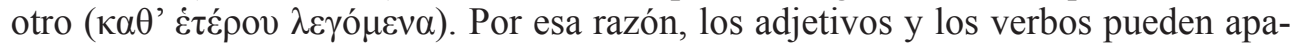
recer en posición atributiva ( $\mathrm{vg}$. 'cuaderno útil, cuaderno desgastado') o constituir predicados adscriptivos ( $\mathrm{vg}$. 'es útil, está desgastado'), a diferencia de los sustantivos ( $v g .{ }^{*}$ 'cuaderno utensilio', *'es desgaste') ${ }^{18}$. Por lo demás, esto justifica en cierto sentido que Aristóteles igualara los predicados verbales simples a las respectivas

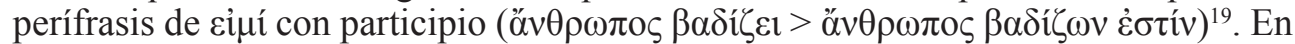
efecto, dichas perífrasis aportan categorías gramaticales similares a las del predicado simple, y los verbos auxiliados en ellas dan a conocer, en términos generales, el mismo significado que los verbos en forma finita.

Las perífrasis con eỉní también pueden ser caracterizadas como estructuras locativas. Las construcciones auxiliares en general concatenan verbos, yuxtaponen verbos y cláusulas, fusionan cláusulas coordinadas o combinan verbos con grupos nominales que desempeñan roles temáticos determinados (Anderson 2006: 9-12). Y las perífrasis con eỉuí parecen pertenecer al último de estos grupos, ya que sitúan a un sujeto en condiciones determinadas mediante formas nominales del verbo. Por

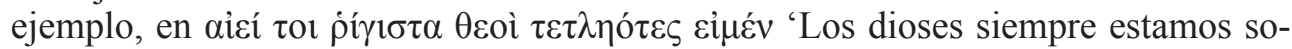
portando las más terribles penas' (Il. V 873), eỉnév inscribe al sujeto en un estado descrito por el participio activo $\tau \varepsilon \tau \lambda \eta$ ó $\varepsilon \varepsilon$. Algo similar ocurre con las perífrasis de infinitivo. Algunos infinitivos griegos surgieron de sustantivos deverbales en caso locativo (Horrocks 2014: 10), pero todos ellos, cuando aparecen sueltos, suponen marcas casuales (Smyth 1920: 438) que sirven para definir contextos deónticos o

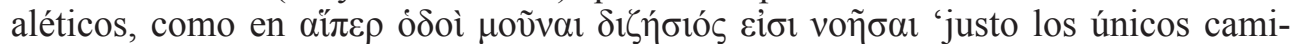
nos de investigación que pueden ser pensados' (B2.2), cuya estructura es locativa: 'justo los únicos caminos de investigación que están para ser pensados'. Asimismo, las construcciones modales con cláusulas de infinitivo pueden ser vistas de manera

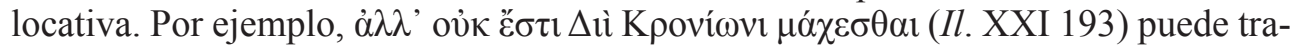
ducirse como 'pero no es posible/no es lícito luchar contra Zeus Cronida', o incluso como 'pero no se puede/no se permite luchar contra Zeus Cronida', pero el verbo

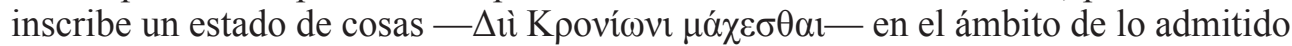
(por el orden cósmico): 'pero no cabe luchar contra Zeus Cronida', 'pero no ha(y) lugar para luchar contra Zeus Cronida'.

Aun concediendo que las construcciones existenciales y auxiliares con sỉuí puedan ser explicadas a partir de oraciones copulativas o locativas, la frontera entre estas últimas no se puede ignorar. Es cierto que la distinción entre atributo y argumento

17 Cf. Lyons (1968: 11), Robins (1997: 32) y Luthala (2000: 32, 46).

18 Otra cosa es que los adjetivos y los verbos puedan sustantivarse mediante determinantes para constituir sintagmas con capacidad referencial, como los que aparecen en las oraciones ecuativas, como las clasificatorias ( $v g$.

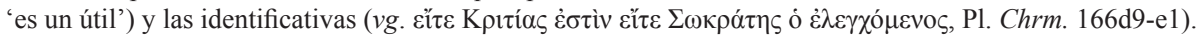

19 Véase Aristot. Int. 21a38-21b10 y Metaph. V 7 1017a27-30. 
locativo no siempre es clara ${ }^{20}$, pero desatenderla quebranta la sintaxis. Afortunadamente, no se necesita difuminar ese límite para englobar todas las construcciones con sỉuí. Basta con que el verbo cumpla una función de apoyo en oraciones locativas para que estas puedan ser asignadas al mismo género que las oraciones nominales (con o sin verbo expreso), es decir, al género de las oraciones de predicado no verbal. Y efectivamente hay construcciones locativas o existenciales griegas que prescinden del verbo cuando este solo proporcionaría información evidente. La construcción

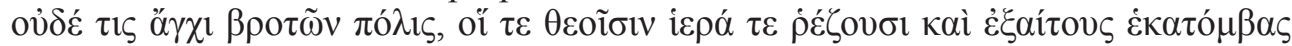
(Od. V 101-102) no tiene verbo, pero, si lo tuviera, sería estativo y marcaría tiempo presente, número singular y modo indicativo: 'No (queda) cerca ninguna ciudad de hombres que realicen ofrendas a los dioses y extraordinarias hecatombes'.

Por consiguiente, cabe dudar de la naturaleza verbal de todos los predicados con cỉuí. Considérese Il. I 271-272, que aparentemente contiene una claúsula nominal

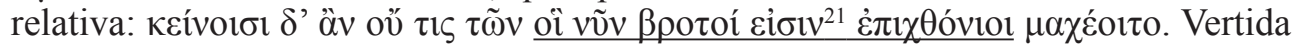
al español, la oración nominal no es del todo convincente porque combina condicio-

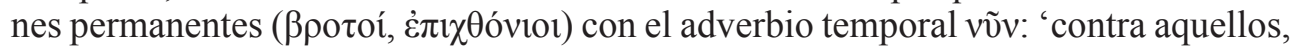
ninguno de los que ahora son mortales terrestres podría pelear'. Dadas las peculiaridades del español, tal vez sería mejor elidir el verbo y convertir el adverbio en locución: 'contra aquellos, ninguno de los mortales terrestres de ahora podría pelear'. Pero si queremos conservar el verbo, una oración locativa resulta más natural debido al prefijo del atributo غ̇ंı- $\chi \theta$ óviov: 'contra aquellos, ninguno de los mortales que se encuentran ahora sobre la tierra podría pelear'. Sin embargo, nótese que ninguno de los factores decisivos atañe a la semántica del verbo, desechable en la oración nominal, pero también en la otra: 'contra aquellos, ninguno de los mortales ahora sobre la tierra podría pelear' (compárese 'Ninguno de los presentes en esta sesión tiene voto').

Hemos visto que eỉuí se construye de varias maneras, pero también que las diferencias semánticas entre sus construcciones no recaen precisamente en el verbo, sino en los demás elementos oracionales. Hengeveld (1992: 73-126), por ejemplo, las haría depender de los argumentos y los predicados en cuestión: los argumentos o sujetos representarían individuos, estados de cosas, contenidos proposicionales o actos de habla; los predicados manifestarían propiedades, condiciones, referencias, relaciones, predicaciones, proposiciones o cláusulas; pero el verbo presentaría información eminentemente gramatical y podría ser omitido cuando dicha información fuera provista por las construcciones mismas o por el contexto.

Aristóteles concebía las oraciones con cỉuí de manera semejante ${ }^{22}$. Consideraba que los verbos ( $\rho \eta ́ \mu \alpha \tau \alpha)$ en general tenían la función de marcar tiempo ( $\chi \rho \cos \varsigma$ ) en la oración; de otro modo, se reducían a palabras (óvó $\mu \alpha \tau \alpha$ ) con significado léxico

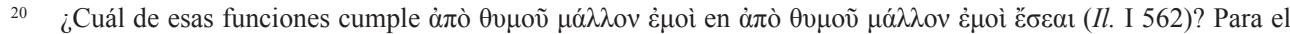
español, véase NGLE 37.8b-c.

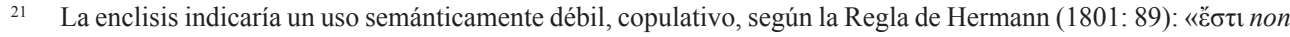
est simpliciter copula, sed adiunctum habet praedicatum, et significat nunc exstat, nunc revera est, nunc licet». Esa regla «es seguida por los editores modernos, pero no es mencionada por los gramáticos antiguos y ha sido disputada» (Devine \& Stephens 1994: 356). En efecto, la acentuación de દỉní es una cuestión prosódica que se relaciona con aspectos sintácticos y pragmáticos, pero no necesariamente semánticos (véase Hdn. Gr. III 1.553, 2.22); coincide con la indefinición del sujeto y cumple funciones discursivas, como la focalización (Kahn 2003: $\mathrm{x})$. En cambio, la enclisis se corresponde con la anteposición de palabras funcionalmente relevantes, como ov̉,

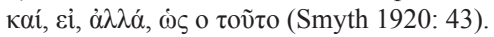

22 Cf. Lenci (1998: 235-242). 
o contenido noemático. Sin embargo, zỉ

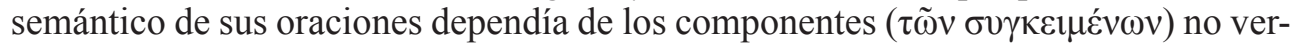
bales de las mismas. Recordemos Int. 16b6-10, 19-25:

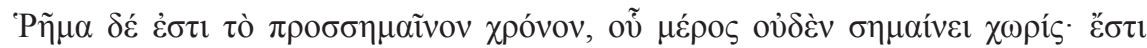

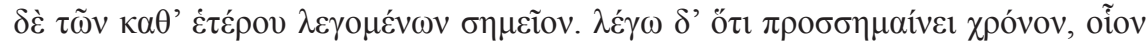

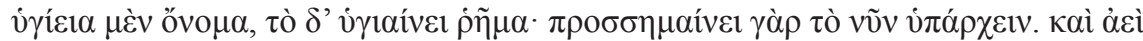

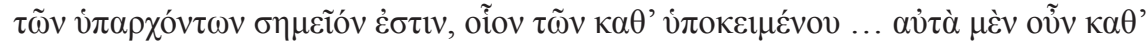

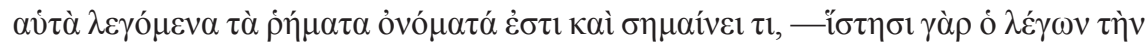

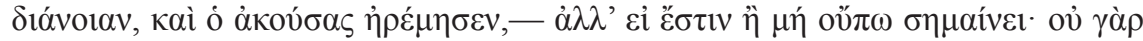

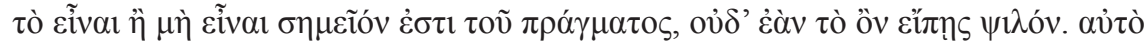

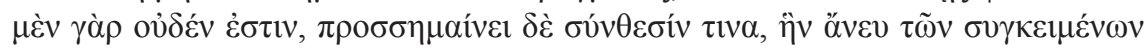

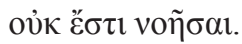

Verbo es lo que aporta significado temporal, y ninguna de sus partes significa de manera independiente; es signo de las cosas que se dicen conforme a otro. Digo que aporta significado temporal en el sentido de que 'sanidad' es un nombre, pero 'sana' es un verbo porque aporta el significado de 'tener lugar ahora'. Y siempre es signo de las cosas que tienen lugar: por ejemplo, de las correspondientes a un sujeto ... Ahora bien, los verbos mismos, dichos por sí mismos, son nombres y significan algo - pues quien los dice fija el pensamiento y quien los escucha atiende-, pero de ningún modo expresan si [algo] es o no [es]: pues ni siquiera 'ser' o 'no ser' son signos de la realidad, ni aunque uno diga 'que es' a secas. Por sí mismo, en efecto, ['ser'] no es [i.e. no significa] ninguna [realidad], sino que designa una composición que no puede ser pensada sin sus componentes.

No cabe duda de que eỉ $\mu$ í indicaba tiempo. Il. I 70 cuantifica universalmente los hechos en función del presente, el futuro y el pasado, sustantivando participios de

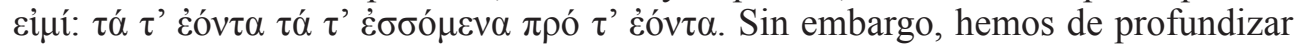
en ese significado temporal por dos razones: de un lado, el verbo griego expresa dos categorías gramaticales relacionadas con el tiempo, a saber, el tiempo y el aspecto ${ }^{23}$; de otro lado, la distinción entre aspecto léxico y gramatical no es del todo clara y se enturbia cuando es vista diacrónicamente. Examinemos, pues, la información dada por sỉuí al margen de «los componentes» de sus oraciones.

\section{La información aportada por \&iıú a las oraciones}

En el Tractatus, Wittgenstein (2018 [1921/22]: 3.323-325) condenó la posibilidad de presentar distintos «símbolos» (Symbole) mediante el mismo «signo» (Zeichen). Habiendo notado que voces idénticas difieren en su distribución cuando son usadas como nombres (vg. Grün) o como adjetivos (vg. grün), aplicó un concepto análogo de equivocidad al verbo sein, que, en su opinión, cumplía tres funciones distintas: la copulativa, la ecuativa y la existencial. Sin embargo, los verbos como sein no representan por sí mismos ninguna clase de predicación, ni la adscriptiva ni la ecuativa,

23 Justo porque el tiempo y el aspecto son categorías gramaticales distintas, y porque el participio no expresa tiempo

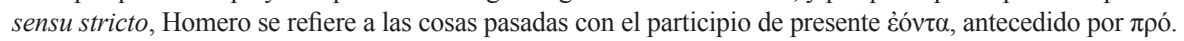


sino, en todo caso, nociones de otro tipo. Por ejemplo, comparando 'la manzana es verde' con 'la manzana está verde', captamos una diferencia semántica o pragmática entre 'ser' y 'estar' ${ }^{24}$ y nos resulta evidente que debemos usar el segundo verbo para hablar de 'la inmadurez de la manzana'. Pero ¿cómo ilustraríamos esa discrepancia en alemán? Podríamos intentarlo con Der Apfel ist grün y Der Apfel ist unreif, pero grün significa tanto 'verde' como 'inmaduro' y explicitar las acepciones del adjetivo 'verde' no es lo mismo que señalar la diferencia entre ambas cópulas. Para reproducir esa diferencia, lo mejor es acompañar la cópula alemana con un adverbio que evidencie la transitoriedad del estado presentado por 'estar': Der Apfel ist grün y Der Apfel ist noch grün.

Por su parte, los filósofos griegos distinguían entre cỉuí y otros verbos funcional-

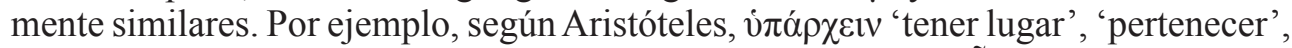
'corresponder', servía para asociar los mismos términos que cĩval, pero este verbo no era intercambiable por aquel ${ }^{25}$. Dado que í $\alpha \rho \rho \omega$ regía dativo, su estructura temática se manifestaba al invertir los términos ( $c f . \dot{\alpha} \nu \tau \tau \sigma \tau \rho \varepsilon ́ \varphi \omega)$ y traía consecuencias importantes, pues asignaba roles semánticos al sujeto de la proposición. Efectiva-

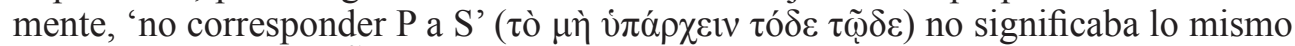

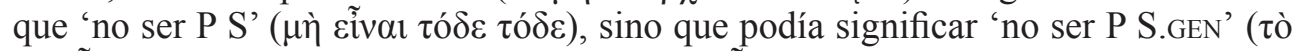

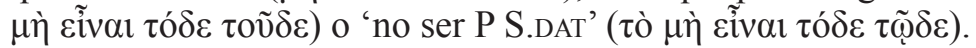

Ahora bien, aunque identificar comparativamente la información expresada o no expresada por cíuí puede ayudarnos a elucidar el concepto griego de 'ser', semejante exploración también parece contravenir la conclusión alcanzada en el apartado anterior, a saber, que cỉ uí no aportaba contenido semántico al predicado. Por tanto, cabe investigar si cỉní era un elemento gramatical completamente vacío de significado. Ciertamente, se dice que los verbos copulativos, a diferencia de los semicopulativos, carecen de contenido léxico y pueden ser removidos de la oración sin mengua semántica alguna, pero los filósofos griegos oponían 'ser' a 'devenir' y eso nos permite conjeturar que eỉuí tenía rasgos semánticos distintivos en algún sentido ${ }^{26}$. ¿Por qué nos remite ese verbo a la idea de 'duración' cuando parece tener significado propio? ¿Por qué a veces requerimos verbos, adverbios o perífrasis con matices durativos para traducirlo adecuadamente ${ }^{27}$ ? Tal vez la etimología resuelva nuestras dudas ${ }^{28}$.

24 Véase NGLE 37.7. Explicación semántica: ‘ser verde’ es un predicado de individuo, un rasgo estable o inherente al sujeto; 'estar verde' es un predicado de estadio, un estado momentáneo que resulta de un cambio o transformación. $C f$. Porroche Ballesteros (1988: 14-15) y Demirdache \& Uribe-Etxebarria (2000: 179). Explicación pragmática: en tanto que 'ser' presenta información sobre el sujeto, 'estar' introduce estados de cosas o asuntos en la conversación: por ejemplo, ante la pregunta ‘¿Qué sucede?', la respuesta 'Juan es malo’ es inadecuada, a diferencia de 'Juan está malo' (Maienborn 2003: 146-147). Comoquiera que sea, 'estar' procede del lat. stare 'estar de pie', 'estar situado', y fue usado originalmente en contextos físicos (NGLE 37.8a); quizá por ello sirve para inscribir los estados en el curso de los acontecimientos.

25 Véase APr. I 36 48b2-4 y 48b27-49a5. Cf. Top. II 1 109a11-26.

26 Sobre la noción de 'significado gramatical', véase Lyons (1968: 435-436). Sobre el aporte no léxico de las cópulas a sus predicados, véase Pustet (2003: 6).

27 He aquí algunos ejemplos:

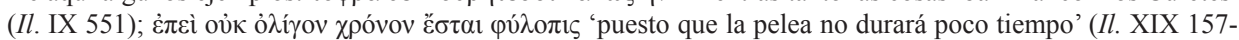

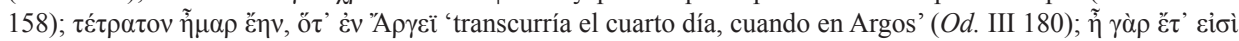

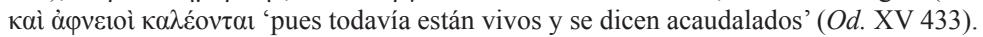

28 La etimología puede ser útil en este sentido. He aquí un ejemplo: el verbo ě $\chi \omega$ proviene de la raíz *seĝh-, que denota 'manejo' o ‘dominio' ( $c f$. skill, Sieg), y las oraciones posesivas con él reflejan esa etimología. En ellas, lo poseído tiende a ser concreto, inanimado y controlable por un posesor humano, mientras que lo asignado en las oraciones "posesivas" con cỉuí tiende a ser abstracto, animado y no controlable por un "posesor" (cf. Kulneff-Eriksson 1999: 24-29, 144). 
Algunas lenguas usan pronombres o partículas deícticas para unir sujetos y atributos, pero las indoeuropeas se valen de verbos con formas desarrolladas a partir de la raíz * he es-: ásti y ásmi (sánscr.), est y sum (lat.), ist y sein (al.), is y am (ingl.), est y sommes (fr.), è y siamo (it.), es y somos (esp.). El paradigma de tales cópulas suele ser supletivo: por ejemplo, las formas inglesas be y was se desprenden de raíces con significado distinto, a saber, de ${ }^{*} b^{h} w_{\text {weh }}-$ 'crecer' o 'surgir' y de $* h_{2}$ wes- 'permanecer' o 'hacer noche'29. Pero todas las formas de eỉuí se derivan de *hes-, una raíz de poco contenido léxico pero constitutiva del verbo imperfectivo *h ésmi (Ringe 2017: 33). Por lo tanto, la información que buscamos podría residir en el aspecto verbal y manifestarse léxica, morfológica y sintácticamente ${ }^{30}$. Abordemos primero el aspecto léxico o modo de acción, porque las marcas flexivas del aspecto morfológico o desinencial podrían haber resultado de la gramaticalización de raíces con significado léxico ${ }^{31}$ y porque el aspecto sintáctico o perifrástico depende de la unión de dos o más verbos.

La noción de 'aspecto léxico' o Aktionsart se refiere al tipo de estado de cosas expresado por el verbo y los demás elementos del predicado. Por ejemplo, 'correr una milla' y 'correr durante 30 minutos' no pertenecen a la misma Aktionsart, pues 'una milla' remite al término de la carrera, pero 'durante 30 minutos' alude más bien a la extensión temporal de una actividad, en este caso, de la acción de correr. Atengámonos a la clasificación de Vendler $(1967)^{32}$ y digamos que hay cuatro aspectos léxicos en función de la duración, la dinamicidad y la telicidad de los predicados, a saber: estados, consecuciones, realizaciones y actividades. A grandes rasgos, las situaciones dinámicas comprenden fases, las durativas se mantienen inalteradas a través del tiempo y las télicas implican límites.

Tabla 1. Rasgos semánticos del aspecto léxico

\begin{tabular}{|l|l|l|l|}
\hline & Duración & Dinamicidad & Telicidad \\
\hline Estados (vg. 'Estar en vigor') & sí & no & no \\
\hline Consecuciones (vg. 'Arribar a un destino') & no & sí & sí \\
\hline Realizaciones (vg. 'Demoler un edificio') & sí & sí & sí \\
\hline Actividades (vg. 'Pensar en un objeto') & sí & sí & no \\
\hline
\end{tabular}

Tipificar, asignar y comprobar el aspecto léxico es complicado, pero aquí solo nos interesa que los predicados no perifrásticos con sỉ $\mu$ í son estados. Frases como 'ser algo', 'ser de cierta clase', 'ser de una manera' o 'estar en determinada situación' denotan condiciones mantenidas a través del tiempo. Por lo mismo, es comprensible que los griegos opusieran 'ser' a 'devenir' ${ }^{33}$. El paradigma de eỉ í $^{2}$ no incluye siquiera la raíz ${ }^{*} b^{h} w_{e} h_{2}$, que en griego dio origen al verbo dinámico

29 Cf. Buck (1971: 635-636), Pokorny (1989: 146, 340-341, 1170), Watkins (2000: xxiii, 11, 24, 101), Rix (2001: 98-101, 241-242, 293-294).

30 Cf. NGLE 23.2.

31 Cf. Szemerényi (1987), Kurzová (1993: 16, 119) y Napoli (2006: 50).

32 Esta no es la única clasificación del aspecto léxico y ha sido criticada por centrarse en la relación predicativa. Mourelatos (1978) intentó eliminar sus implicaciones tópicas.

33 Ejemplos clásicos son: Pl. Ti. 27d5-28a1 y Tht. 152d2-e8. 
甲v́œ 'crecer', 'nacer', 'producir naturalmente' (Buck 1971: 635-636; Back 1991: 290). De hecho, el aislamiento de ambos radicales queda reflejado en la división del poema de Parménides, cuya primera parte infiere los atributos de lo ente ( $\tau$ ò

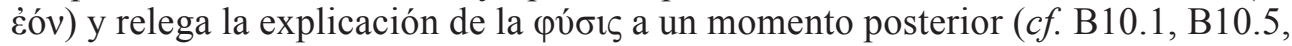
B10.6, B19.1).

Asimismo, es posible que B6 oponga la estatividad de cỉní al aspecto léxico de $\pi \varepsilon ́ \lambda \omega$. Estos verbos suelen traducirse como sinónimos en el poema de Parménides $^{34}$, pero los estudiosos han notado que ambas palabras pertenecen a familias semánticamente muy distintas ${ }^{35}$. Nótese que las voces emparentadas con $\pi \dot{\lambda} \lambda \omega$

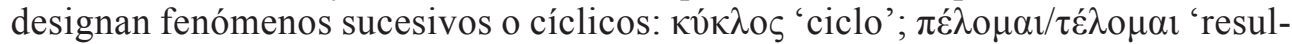

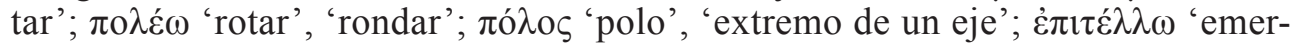
ger'; $\pi \varepsilon \rho \imath \varepsilon \dot{\lambda} \lambda \lambda$ o $\mu \alpha \imath$ 'retornar', 'regresar' (Pokorny 1989: 639). Así es, proveniente de la raíz dinámica y télica * $k^{w} e l$ - 'girar', 'rodar', 'rotar', 'volver', 'retornar' ${ }^{36}$, $\pi \varepsilon ́ \lambda \omega$ habría presentado los acontecimientos como resultados de un proceso, a diferencia de cỉní y a semejanza de cárati (sánscr.), uerto (lat.) y werden (al.) (LSJM 1961: s.u. $\pi \dot{\lambda} \lambda \omega)$. De hecho, Bernabé Pajares (2019: 75) admite que, en

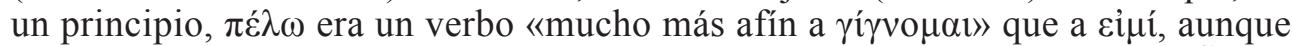
también sostiene que Homero ya empleaba ese verbo como "sinónimo de Eĩval». Sin embargo, cabe cuestionar que $\pi \varepsilon ́ \lambda \omega$ y eỉú fueran sinónimos para Homero. Cunliffe (1963: s.u. $\pi \dot{\lambda} \lambda \omega$ ) consigna que $\pi \dot{\varepsilon} \lambda \omega$ significa to turn, to turn out to be, to come to be, to become, to come into being en los poemas homéricos, y es difícil rechazar esa definición cuando se considera el aspecto léxico de $\pi \varepsilon \dot{\lambda} \omega$. Desde luego, $\pi \dot{\lambda} \lambda \varepsilon i v$ puede traducirse como 'ser' algunas veces: por ejemplo, en $\tau \tilde{\eta} \pi \varepsilon \rho$

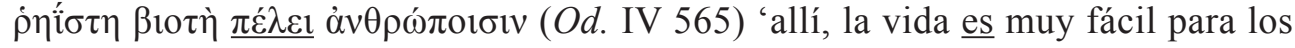
hombres'. Pero, por la misma razón que Der Apfel ist grün es una traducción imperfecta de 'la manzana está verde', la posibilidad de traducir $\pi \varepsilon ́ \lambda \varepsilon ı$ como 'es' no garantiza la intercambiabilidad de esas palabras salva veritate. Es más, la traducción de $\pi \varepsilon ́ \lambda \varepsilon ı$ gana precisión cuando expresa dinamicidad y telicidad. Obsérvese que 'allí, la vida resulta muy fácil para los hombres' presenta, atinadamente, la facilidad como efecto de las condiciones dadas en cierto lugar $(\tau \tilde{\eta})$. Otras veces, $\pi \varepsilon ́ \lambda \varepsilon ı v$ ni siquiera puede traducirse cómodamente como 'ser'. Por ejemplo, algunas expresiones homéricas evidencian el aspecto léxico de $\pi \dot{\lambda} \lambda \omega$ en la medida en que suponen el fin de un evento y aseveran el acaecimiento de otro. Tapia Zúñiga

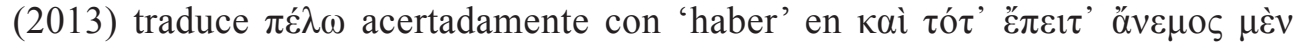

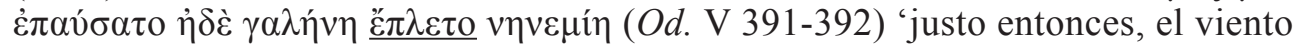
cesó, y calma marina hubo, sin viento'. Pero examinemos la situación descrita por Homero. La calma marina no acontece antes de que cese el viento. No se habla de la calma en sí misma ni al margen de sus límites, como si fuera un estado; se habla de ella como si se tratara de una cosa que sucede a otra. Una vez que cesa

34 Por ejemplo: Diels (2003 [1897]), Untersteiner (1958), Diels \& Kranz (1960), Tarán (1965), Hölscher (2014 [1969]), Mansfeld \& Primavesi (2012 [1983]), Gallop (1984), Coxon (2009 [1986]), O’Brien \& Frère (1987), Cordero (2005), Bernabé Pajares (2007), entre muchos otros.

35 Véase, por ejemplo, Woodbury (1958: 154). Por lo demás, García Calvo (2018: 207) notaba incluso una diferencia gramatical: al menos en el poema de Parménides, $\pi \varepsilon ́ \lambda \omega$ no funcionaría como un verbo copulativo.

36 La raíz * $k^{w} e l$ - trasluce en la palabra ingl. wheel ( $c f$. Watkins 2000: 45; Rix 2001: 386-388), pero no en la gr. $\pi \varepsilon ́ \lambda \omega$. Téngase en cuenta que el fonema labiovelar *[kw-] fue tratado de distintas maneras en la Edad Oscura. El griego prefirió [p-] ante vocales como $o$ у $u$, pero [k-] se encuentra en textos literarios jonios: $\pi \tilde{\omega} \varsigma / \kappa \tilde{\omega} \varsigma, \pi o ́ \tau \varepsilon /$

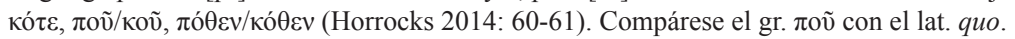


el viento, sobreviene la calma, o incluso regresa. Ahora bien, si tomamos en serio estas observaciones, cabe hipotetizar que B6.8-9 contrasta dos aspectos léxicos y critica a quienes no distinguen entre 'ser' y 'acontecer cíclica o regularmente', quizá al milesio Anaximandro (DK 12 B 1). En efecto, en una sucesión como ... $a \rightarrow b \rightarrow a \rightarrow b \ldots$, un estado de cosas cede su lugar a otro ( $\pi \varepsilon \dot{\lambda} \varepsilon ı v)$-que no a la

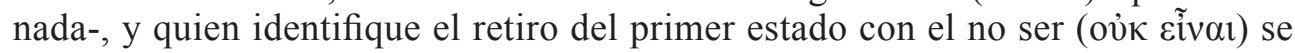
verá forzado a desdecirse cuando ese mismo estado regrese o surja de nuevo ${ }^{37}$. Recuérdese que la diosa califica el curso de los mortales como 'reversible' o 're-

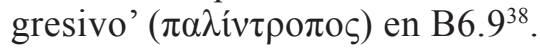

Ahora veamos qué sucede con el aspecto morfológico de cỉuí. El sistema verbal griego marca tiempo y aspecto, entre otras categorías gramaticales. Mientras el tiempo indica si los hechos tienen lugar antes, a la par o después de un momento determinado en función de un acto de habla, el aspecto expresa la manera en que esos hechos tienen lugar. En griego, los aspectos imperfectivo, perfectivo y perfecto coinciden con los temas de presente, aoristo y perfecto. Las formas con valor imperfectivo, como el presente y el imperfecto, destacan la persistencia de los estados de cosas simultáneos, continuos, progresivos o habituales; las formas con valor perfectivo, es decir, los aoristos, acentúan la realización discreta, puntual o en bloque de los hechos; y las formas de perfecto presentan los estados de cosas por su vínculo, a veces causal, con un hecho previo ${ }^{39}$. De acuerdo con semejantes correspondencias, cabe inferir que sỉní no expresaba discontinuidad, terminación ni resultado, porque carecía de aoristos y perfectos. Por lo demás, es probable que esa defectividad

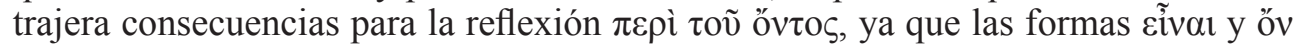
pertenecen al tema de presente y el concepto griego de 'ser' era indisociable de la actualidad. Por ejemplo, lo ente de Parménides «ni era ni será en un momento dado

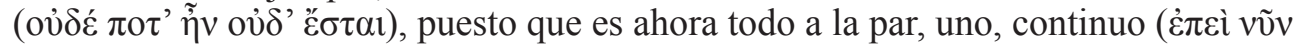

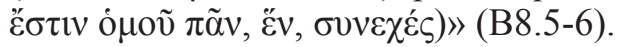

37 La Fenomenología del espíritu relativiza el valor epistémico de la sensibilidad con una idea similar. «Auf die Frage: was ist das Jetzt antworten wir also zum Beispiel: das Jetzt ist die Nacht. Um die Wahrheit dieser sinnlichen Gewißheit zu prüfen, ist ein einfacher Versuch hinreichend. Wir schreiben diese Wahrheit auf; eine Wahrheit kann durch Ausschreiben nicht verlieren; ebensowenig dadurch, daß wir sie aufbewahren. Sehen wir jetzt, diesen Mittag, die ausgeschriebene Wahrheit wieder an, so werden wir sagen müssen, daß sie schal geworden ist» (Hegel 1986 [1807]: 83) 'Así pues, a la pregunta ¿Qué es el ahora? respondemos, por ejemplo: El ahora es la noche. Para probar la verdad de esta certeza sensitiva, es suficiente un experimento sencillo. Ponemos esta verdad por escrito; no puede perderse una verdad por ser escrita; mucho menos porque la guardemos. Si volvemos a mirar ahora, al mediodía, la verdad escrita, tendremos que decir, entonces, que se ha vuelto insípida'. El adjetivo schal significa privado de frescura o sabor, pero también privado de sustancia o espíritu. Hegel asocia la verdad de los juicios sobre los objetos de la percepción sensorial con lo perecedero.

38 Mi interpretación se desvía de la norma y desencadena problemas que no puedo abordar ahora. La defensa de semejante propuesta debería justificar la no-sinonimia entre $\pi \varepsilon ́ \lambda \omega$ y cỉ $\mu$ í fuera del poema de Parménides, probar que $\pi \varepsilon ́ \lambda \omega$ puede ser consistentemente traducido con verbos dinámicos o télicos en B8.11, 18, 19 y 45, y elaborar una explicación de la filosofía parmenídea que acoja la nueva versión de B6. Quien conozca el debate académico en torno al fragmento, entenderá que una alternativa razonable (y discutible al igual que las otras) consiste en reivindicar un «tercer camino» de investigación -'suceder'-, o sea, reivindicar la verosimilitud de una historia natural que aplique los conocimientos adquiridos a través del «primer camino» que puede plantearse a priori -'ser'-, habiendo entendido por qué el «segundo camino» - 'no ser'-, también planteado a priori, es necesariamente inviable. Los interesados pueden recurrir, en principio, a Reinhardt (1977 [1916]: 35-36), Tarán (1965: 59-61), Nehamas (1981), Cordero (2005: 126 y ss.) y Wedin (2011, 2014).

39 En términos generales, sigo a Comrie (1998: 4-12), Rijksbaron (2002: 1) y Napoli (2006: 28-29). 
¿Pero cómo entendían los filósofos griegos la actualidad de lo ente? ¿Acaso distinguían entre tiempo, aspecto y significado? Sin pretender agotar el asunto, consideremos P1. Ti. 37e1-38b3 a manera de ejemplo:

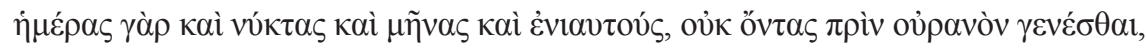

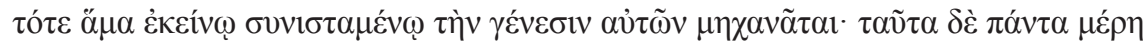

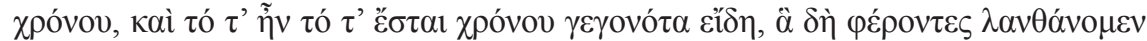

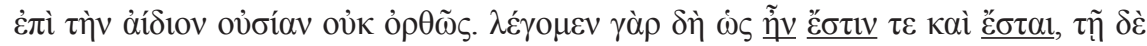

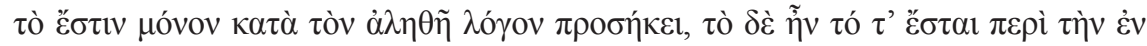

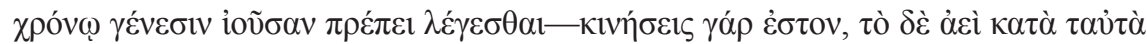

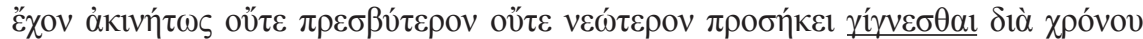

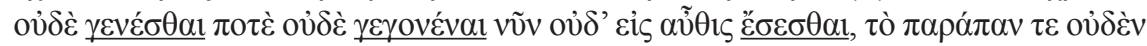

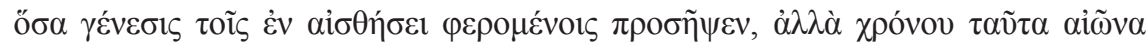

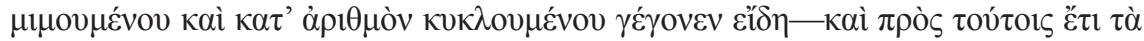

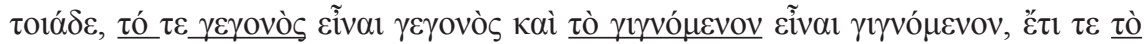

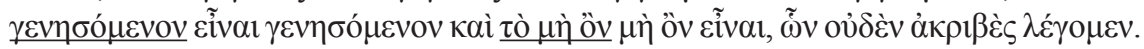

Pues como no había días, noches, meses ni años antes de que se generara el orbe, al momento de la constitución de este se tramó la generación de aquellas cosas. Todas ellas son fracciones generadas del tiempo, y tanto 'era' como 'será' son especies generadas del tiempo, que, sin notarlo, transferimos incorrectamente a la entidad perpetua. En efecto, con naturalidad decimos que era, es y será, pero solo le corresponde 'es' de conformidad con el razonamiento verdadero, mientras que decir 'era' y 'será' resulta apropiado para la generación que adviene en el tiempo- en efecto, ambas [expresiones] son [i.e. implican] mutaciones; pero a lo que se mantiene siempre inmutable de conformidad con lo mismo no le corresponde volverse más viejo ni más joven a través del tiempo, ni originarse en un momento dado, ni ser generado ahora, ni ser en el futuro a partir de aquí, ni condición alguna en absoluto de cuantas aporta la generación a las cosas que se presentan a la sensibilidad; esas son más bien especies generadas del tiempo que imita a lo eterno y da vueltas en razón del número-, y además de esas cosas, también [decimos] estas: que lo que se ha generado es algo que se ha generado y que lo que se genera es algo que se genera, asimismo que lo que se generará es algo que se generará y que lo que no es es algo que no es, ninguna de las cuales decimos con precisión.

Timeo no aborda la diferencia entre 'ser' y 'devenir' en términos gramaticales, sino semánticos y dependientes de cierta cosmovisión. Sostiene que referirse a la

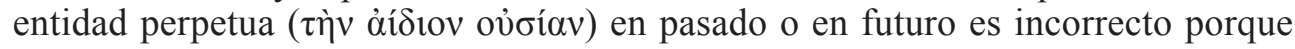

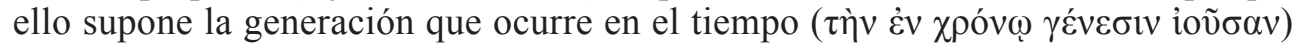
-y la anterioridad y la posterioridad no brindan información sobre la oủ $\sigma i ́ \alpha$, que se mantiene perpetuamente en el mismo estado ${ }^{40}$. Timeo interpreta la diferencia entre ह̌ $\sigma \tau \imath$ y cualquier forma verbal que suponga generación como una oposición entre

$40 \quad$ El pasado de eỉuí pertenece al tema de presente y hay usos filosóficos que parecen explotar la imperfectividad de $\tilde{\eta} v$ para aludir a la prioridad lógica o incluso ontológica o de naturaleza: por ejemplo, la expresión aristotélica

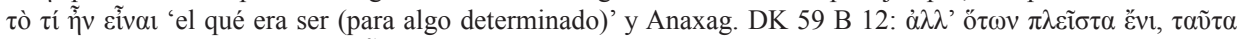

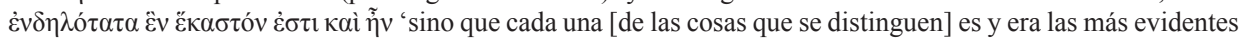
de esas muchas [materias] en que consiste’. 
'continuidad' y 'discontinuidad', condiciones que asemeja a ser y no ser. Por ello, al final de la cita considera impreciso atribuir 'ser' y 'devenir' a un mismo sujeto ( $\tau$ ó), y no profundiza en la información gramatical de las formas $\gamma \varepsilon \gamma o v o ́ \varsigma$ (perfecto), $\gamma \imath \gamma v o ́ \mu \varepsilon v o v$ (presente) y $\gamma \varepsilon v \eta \sigma o ́ \mu \varepsilon v o v$ (futuro). Hay otros pasajes célebres que sí podrían distinguir 'ser' y 'devenir' en términos aspectuales: por ejemplo, es posible que Aristot. Int. 18a27 suponga una distinción aspectual entre las cosas que son (őv $\tau \omega v$, imperfectivo) y las cosas que pasaron ( $\gamma \varepsilon v o \mu \varepsilon ́ v \omega v$, perfectivo), ya que el participio öv $\tau \omega v$ no marca tiempo en sentido estricto. Pero ese no es el caso del Timeo. Es obvio que Platón reconocía las marcas temporales de ह̌ $\sigma \tau \imath v$ (presente), $\tilde{\eta} v$ (pasado) y $\check{\varepsilon} \sigma \tau \alpha$ l (futuro), pero incluso si hubiera distinguido los aspectos de

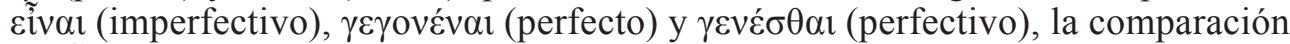

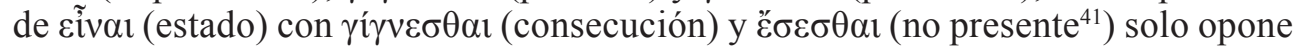
la presencia y la ausencia de entidad a través del continuo temporal. Comoquiera que fuese, Platón concebía la entidad a imagen de la duración (sin dinamicidad ni telicidad) y de ciertas formas de imperfectividad (como la continuidad ${ }^{42}$ ), es decir, como algo perpetuamente presente o carente de todo límite interno. Esa repre-

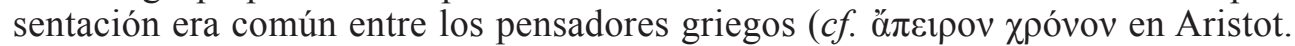

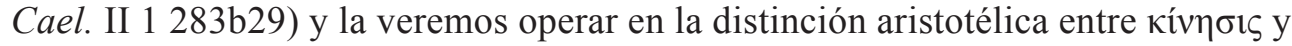

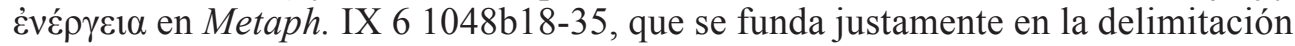
inherente al cambio.

Por último, el aspecto sintáctico se manifiesta en predicados complejos donde el verbo enfoca «el inicio, el término o el curso mismo de las situaciones, así como su interrupción, su reiteración o su cese» (NGLE 1.8ñ). En el caso que nos ocupa, cìú

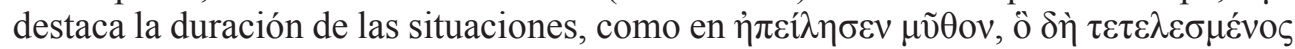

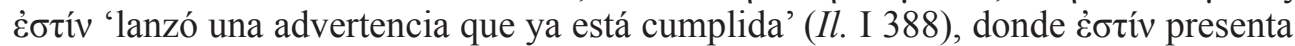
el cumplimiento de la advertencia como un estado, mientras el valor resultativo del predicado recae en el participio perfecto $\tau \varepsilon \tau \varepsilon \lambda \varepsilon \sigma \mu \varepsilon \dot{v}$ os. Piénsese en el Zustandspassiv alemán en oposición al Vorgangspassiv. Otro ejemplo: en ì $\gamma(\gamma v o ́ \mu \varepsilon v o v \pi \alpha \rho ’ \eta j \mu i ̃ v ; ~ ‘ ¿ O$ no está sucediendo eso ante nosotros?' (Pl. Phlb. 39c1-2),

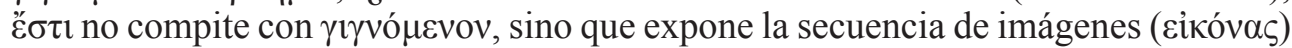
en cuestión de manera imperfectiva, como algo progresivo. Compárese lo anterior con el aspecto sintáctico de los predicados con $\pi \dot{\lambda} \lambda \omega$, que opera más bien como un

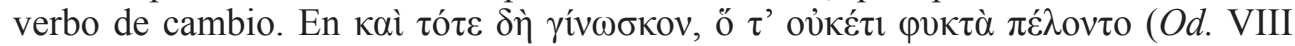
299), la oración sustantiva admite una lectura perifrástica con sentido modal. El ad-

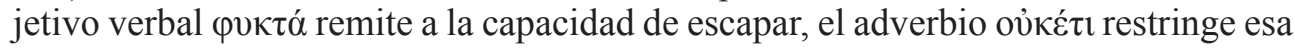

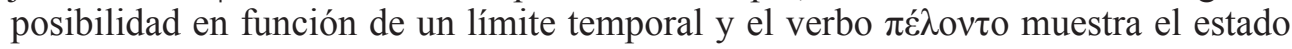
de cosas como un resultado: 'Y entonces se dieron cuenta de que ya no se hallaban en la posibilidad de escapar/de que ya no les resultaba posible escapar/de que ya no quedarían a salvo'.

Hasta ahora hemos sacado tres conclusiones: 1) el verbo cỉ función eminentemente gramatical en las oraciones, 2) cuenta con una neutralidad léxica notable, y 3 ) aporta duración e imperfectividad a los predicados. Sin embargo, la cuestión de relevancia filosófica es cómo y en qué medida repercutieron esos

41 Según Smyth (1920: 427) y Rijksbaron (2002: 1), el futuro expresa el mismo aspecto que el presente. Al parecer, la voz media del futuro de cíuí, que terminaría imponiéndose sobre el paradigma entero después del Helenismo (Horrocks 2014: 154), solo muestra que 'ser' no es la acción de un sujeto.

42 Sobre la semántica y la sintaxis de la continuidad, véase Arche (2014: 810-817). 
rasgos en las ontologías de Parménides, Platón y Aristóteles, pues en el transcurso de esta investigación hemos llamado la atención sobre las correspondencias entre las propiedades lingüísticas de cỉní y la concepción griega de lo ente.

\section{Bases para la interpretación lingüística de la ontología griega}

Las peculiaridades de cỉú se manifiestan en el poema de Parménides. En B8.3, el participio presente غ̇óv reafirma el vigor del todo ${ }^{43}$ y $\dot{\sigma} \sigma \tau \imath$ presenta los atributos

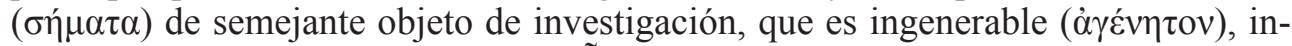

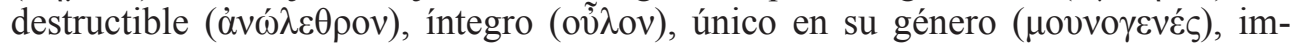

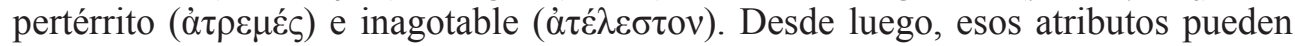
deducirse del concepto de un orbe absolutamente pleno, pero la neutralidad léxica y el aspecto verbal de eíuí son cruciales para la doctrina parmenídea de lo ente.

La viabilidad del camino «según el cual es y no es posible que no sea» (ő $\pi \omega \varsigma$

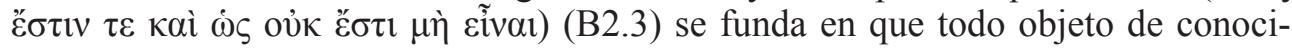
miento, designación, manifestación, enunciación o pensamiento ${ }^{44}$ debe subsistir en calidad de 'algo'. Por el contrario, la inviabilidad del camino «según el cual no es y

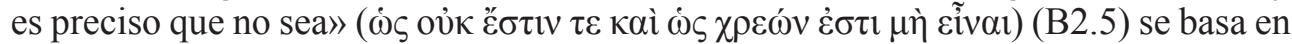
la imposibilidad de conocer, designar, manifestar, enunciar o pensar lo que no subsiste de ningún modo, lo que no puede ser aprehendido en absoluto ${ }^{45}$. De ahí que la

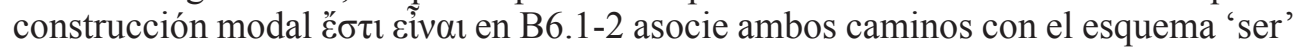
+ determinación, cuya expresión gramatical básica es la predicación: «Urge decir y entender que [el caso] es que es: pues ser [algo] es posible, pero [no ser] nada no [lo]

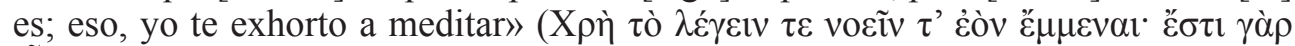

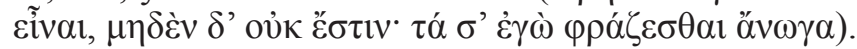

Ahora bien, los predicados con eỉuí denotaban duración y presentaban las cosas de manera imperfectiva, así que Parménides identificó el significado de ese verbo con la subsistencia de los objetos que aprehendemos con el intelecto (B4). A su entender, dicha subsistencia no solo era la condición común a todo lo ente en cuanto ente, sino que también ponía de manifiesto un vigor ininterrumpible por delimitaciones establecidas con respecto al tiempo, la naturaleza, el lugar o la apariencia. Por eso atribuía un valor nominal a la discontinuidad de los predicados particulares, dinámicos y télicos.

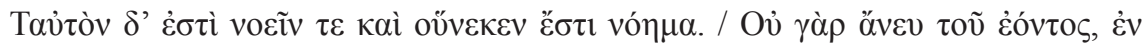

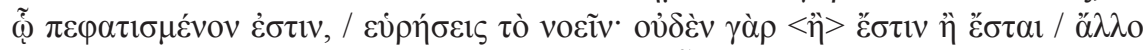

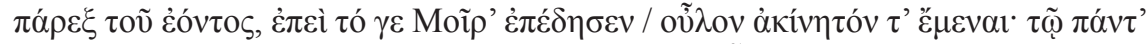

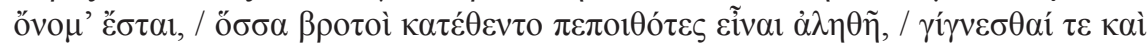

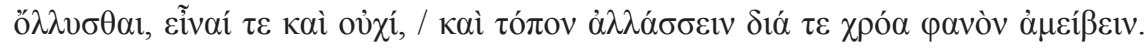
(B8.34-41)

Lo mismo es pensar y el pensamiento de que [algo] es. En efecto, sin lo ente, en lo que está expresado, no hallarás el pensar: pues ninguna otra cosa hay o habrá

\footnotetext{
43 Cf. Metaph. I 5 986b10-31.

44 Cf. $\gamma \imath \gamma$

$45 \quad C f$. Kirk, Raven \& Schofield (2003: 246).
} 
fuera de lo ente, ya que Moira lo obligó a ser íntegro e inmutable; frente a ello, será nombre todo cuanto los mortales hayan supuesto, estando convencidos de que es verdadero: generarse y destruirse, ser y no $[\mathrm{ser}]^{46}$, cambiar de lugar y transmutar la faz luciente.

En este sentido, Bernabé Pajares (2019: 74) sugiere con razón que el infinitivo Eĩvar era visto como hiperónimo de las cosas que son, es decir, como un «lexema que representa en el plano del significante semas comunes a dos o más unidades léxicas». Parménides no tenía una concepción puramente formal de la 'cópula', de modo que relacionó la subsistencia (sema) de las determinaciones presentadas por cỉuí con el aspecto léxico de ese verbo (lexema).

Parménides identificaba el 'ser' con el vigor común a todo lo subsistente y el 'no ser' con la interrupción de ese vigor (B8.24-25 y B8.32-33). Por ello sostenía que lo ente está presente en su integridad (B8.5-6) y rechazaba el camino a través del cual "'suceder' y 'no ser' son considerados usualmente lo mismo y no lo mismo»

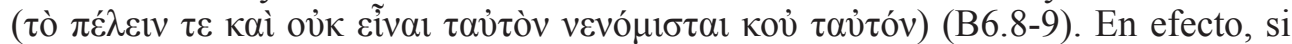
la interpretación aquí ofrecida es correcta, B6 reprocha la confusión de suceder con no ser precisamente porque la alternancia de estados ( $c f$. $\alpha \mu$ oı $\beta \alpha \delta$ óv en B1.19) no

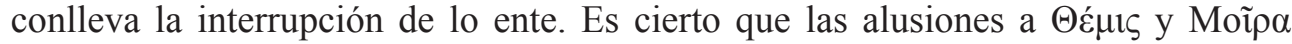
permiten hablar de la predisposición y la predeterminación de lo ente y leer la ontología parmenídea en clave actualista ( $c f$. B7.1), como probablemente hicieron los megáricos ${ }^{47}$, pero la remisión de Parménides al 'ahora' (võv) pretendía más bien

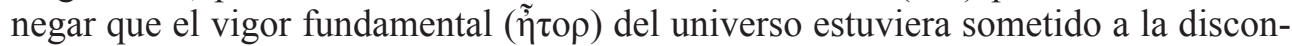
tinuidad expresada por los verbos como $\pi \varepsilon ́ \lambda \omega$. Recuérdese que el participio presente ćóv expresaba sobre todo aspecto. Parménides tenía una concepción cíclica de la naturaleza (B5) y veía el mundo fenoménico a la manera de Hesíodo (Th. 736-757), es decir, como la coordinación de episodios periódicos (B1.11-21). Por ello aseguraba que lo ente persiste a través de todo (B1.31-32) y describía su inevitable continuidad, metafóricamente, como un encierro, como la unión de los extremos de un grillete, como el encadenamiento de los ciclos (B8.13-15, 22-33, 37-38, 42, 49). Naturalmente, en este contexto cobran relevancia las otras dos figuras modales del poema ${ }^{48}: \Delta i ́ \kappa \eta$

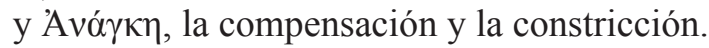

La ontología parmenídea cumplía un propósito metodológico. Por un lado, mostraba que solo podemos conocer, designar, expresar, enunciar o pensar lo determinado (B8.34-37). Por otro lado, argumentaba que ni la delimitación de los estados de cosas ni las diferencias semánticas (B8.38-41, 51-59) son soluciones de continuidad en lo ente (B8.42-49). De ahí que Parménides se apegara a la persistencia de lo ente para alcanzar la verdad (B2.4) y observara los $\sigma \eta ́ \mu \alpha-$ $\tau \alpha$ al especular sobre la configuración cósmica y el desarrollo del universo (B4,

46 Evidentemente, se trata de la combinación aditiva, de la unión de ambos.

47 A los filósofos de Mégara no solo se atribuye el actualismo criticado en Aristot. Metaph. IX 3 1046b2936, sino también el fatalismo adjudicado a Diodoro Crono en Cic. Fat. IX (cf. Arr. Epict. diss. II 19.1). Se dice que eran seguidores de Parménides (véanse las fuentes citadas en Gardella 2014: 4) y que su necesitarismo derivaba del eleatismo. Palmer (2009: 100) ha relacionado la ontología parmenídea con el actualismo.

48 Junto a cỉuí, a veces omitido, y complementos oracionales, estos términos (o palabras con la misma base léxica) servían para construir expresiones modales comparables a 'Es forzoso que'. Véase, por ejemplo, Rijksbaron (2002: 102). Estudiosos como Fränkel (1930: 158-169), Lloyd (1987 [1966]: 390) y Mourelatos (2008 [1970]: 160-162) han acertado al tomar en serio el sentido modal de estas figuras mitológicas. 


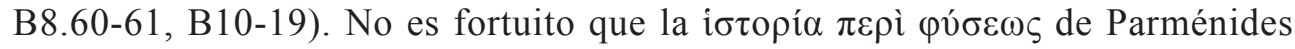
reprodujera la constricción de lo ente (B10.6-7) y evitara segregar los poderes opuestos por convención, a partir de los cuales explicaba las diferencias (B9, B19.3).

Por su parte, Platón no solo opuso 'ser' a 'devenir', sino que trató de probar que un mismo principio subsiste en la diversidad de lo ente y lo no ente ${ }^{49}$. Dando tratamiento matemático al problema metafísico de lo uno y lo múltiple, asumió que la pluralidad reproduce la unidad y explicó la variedad inteligible y sensible como recursión de un factor determinante ( $\tau$ ò $\varepsilon v$ ) en otro factor determinable ( $\theta \alpha ́$ $\tau \varepsilon \rho \circ v)^{50}$. Posiblemente concebía la determinación como subsistencia formal del primer factor en el segundo ${ }^{51}$, porque asociaba la definición de los objetos del arte y la ciencia con la división del entero uno-ente ${ }^{52}$. Es más, que las distinciones de

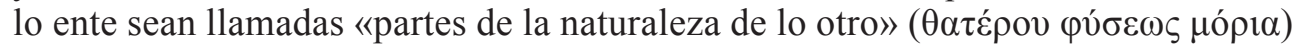
en Sph. 257d4, hace pensar que Platón sí pudo concebir la especificidad de lo ente como producto de la recursión de lo uno en lo otro. Comoquiera que haya sido, el enfoque matemático le permitió explicar la diversidad de lo ente como fraccionamiento de la entidad y el tiempo ${ }^{53}$ y aclarar los detalles lógicos y epistemológicos de lo no ente. De acuerdo con Sph. 257b9-259b6, no enunciamos lo ente mismo, sino determinaciones oponibles entre sí ( $v g$. 'ser tal cosa pero no tal otra'), de

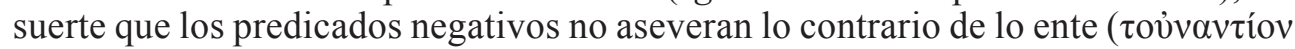

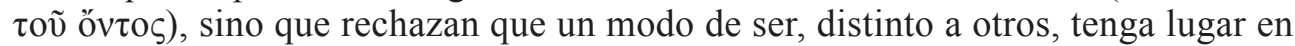
determinadas condiciones.

Evidentemente doy por sentado que Platón propuso una teoría de los principios como la mencionada por Aristóteles en diversos lugares ${ }^{54}$, pero aquí me limitaré a mostrar que una interpretación lingüística del Parménides y el Sofista esclarece la ontología platónica en buena medida. Recordemos que ambas obras fueron catalogadas como diálogos $\lambda$ oүıкoí en la Antigüedad y que, según Prm. 135d8-e4, las

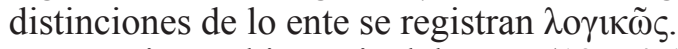

La primera hipótesis del Prm. (137c4-142a8) resulta lingüística y epistémicamente improductiva porque asume un principio que no puede ser distinguido bajo ningún aspecto. Parménides concluye que lo uno simpliciter no es de ninguna

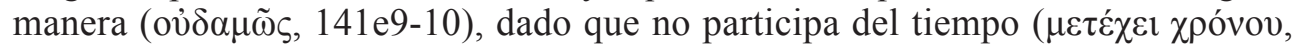

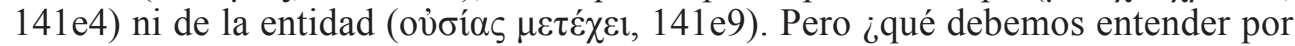
partes o fracciones de tiempo y entidad? Según Sph. 261e4-262a7, ponemos de manifiesto la entidad mediante nombres y verbos. Los primeros designan sujetos de predicación y los segundos expresan acciones, pasiones, experiencias o estados predicables.

49 Para lo ente, véase Prm. 142b1-157b5; para lo no ente qua distinto, véase Prm. 160b4-163b6; para lo no ente qua aparente, véase Prm. 164b4-165e1.

50 Cf. Metaph. I 6 y I 8 989b16-21.

51 La diferencia entre subsistir 'formal' o ‘eminentemente' es neoplatónica ( $c f$. Lloyd 1967: 311) y Proclo la exponía de manera platonizante: «Todo lo que subsiste de algún modo, o bien es de manera arquetípica, como corresponde a la causa, o bien es, en cuanto se da [en un sujeto] o por participación, de manera icónica». En griego:

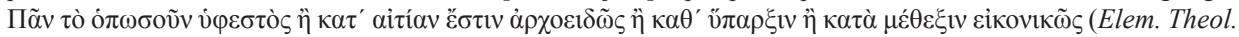
65.1-2).

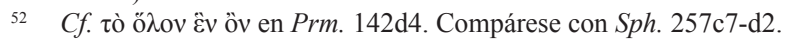

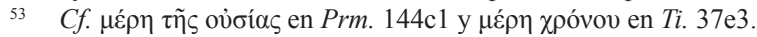

54 Véase Gaiser (1998: 476 y ss.). 


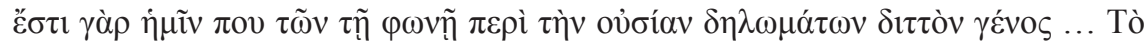

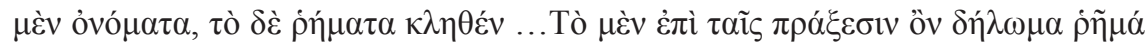

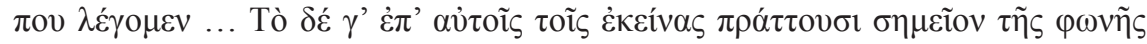
$\dot{\varepsilon} \pi \imath \varepsilon \theta \dot{\varepsilon} v$ ővo $\mu \alpha$.

Pues pienso que, para nosotros, hay dos modos de manifestar la entidad con la voz ... Por un lado, los nombres, por otro los llamados verbos ... Le decimos verbo, pienso, a la que es manifestación de las cosas que se efectúan ... Nombre, en cambio, es la señal de voz aplicada a los que efectúan aquellas $\operatorname{cosas}^{55}$.

La definición platónica de 'nombre' y 'verbo' parece exclusivamente semántica en un principio, pero revela su naturaleza sintáctica cuando el Extranjero alude a la estructura del discurso ( $\lambda$ ó $\gamma$ o $)$ y establece que una secuencia de palabras con sentido debe combinar correctamente ỏvó $\mu \alpha \tau \alpha$ y j́ń $\mu \alpha \tau \alpha$ (Sph. 262a9-d6). Por lo tanto, que la entidad sea dada a conocer mediante nombres y verbos significa que la entidad es registrada mediante categorías léxicas capaces de fungir como sujeto o predicado y que las fracciones de entidad se corresponden con las respectivas distinciones semánticas, sin considerar los determinantes o las marcas flexivas que puedan acompañarlas $^{56}$. De ahí que Platón aborde la división del tiempo por separado: pues el tiempo, categoría deíctica aplicada propiamente a lo cambiante, se manifiesta en la morfología del verbo y no tiene que expresarse léxicamente.

Ahora se comprende en qué sentido es explotada la fragmentación de la entidad y el tiempo en la segunda hipótesis del Prm. (142b1-157b5), que explora la división del entero uno-ente ('ser' + determinación). Mientras que la subsistencia formal de

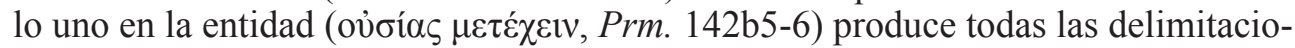
nes posibles del contenido noemático ${ }^{57}$, la subsistencia formal de lo uno en el tiempo da lugar a todas las determinaciones temporales que puedan corresponderle a la entidad. Considérese Prm. 151e7-152a2:

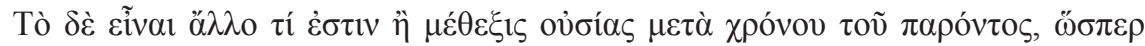

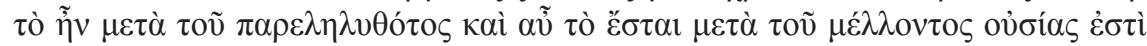

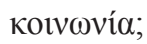

¿Pero 'ser' es algo más que participación de cierta entidad en el tiempo presente, de suerte que 'era' es la asociación con cierta entidad en el pasado y 'será', a su vez, en lo venidero?

Por lo demás, la subsistencia de lo uno en el tiempo involucra el aspecto verbal. Puesto que la persistencia del 'ser' depende de la unidad continua, Platón alude al

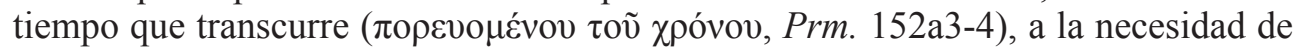

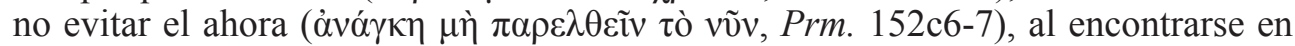

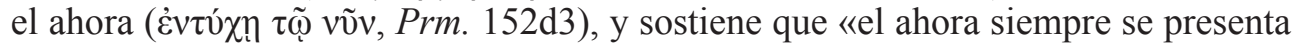
junto a lo uno a través de todo el ser: pues siempre es ahora justamente cuando es»

\footnotetext{
55 La identidad entre predicados y acciones en $S p h$. 262a6-7 es una generalización, ya que Sph. 257b6-7 menciona predicados que no requieren un sujeto agente.

56 Cf. Prm. 142a1-2, 155d4-5, 160e2-4 y 164a7-b1.

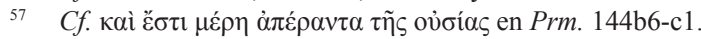




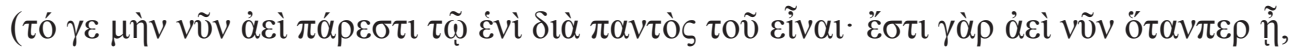
Prm. 152d8-e1). En cambio, como la transitoriedad del devenir se funda en la unidad discreta, Platón utiliza la noción de 'instante' en Prm. 156d3-e3 para describir la delimitación inherente a la generación y la destrucción ( $\left.\gamma^{\prime} \gamma v \varepsilon \sigma \theta \alpha 1, \dot{\alpha} \pi \delta ́ \lambda \lambda v \sigma \theta \alpha 1\right)$,

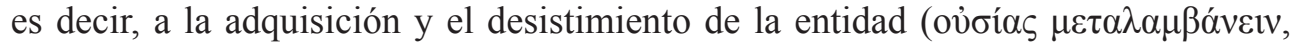

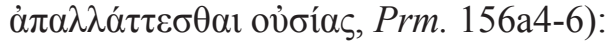

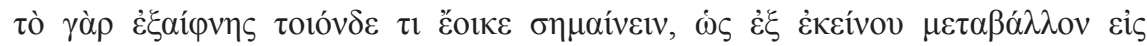

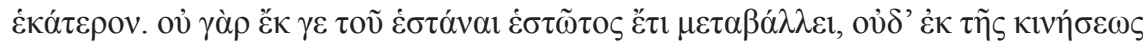

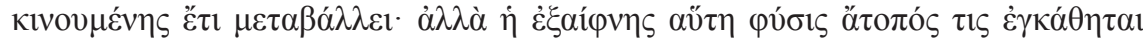

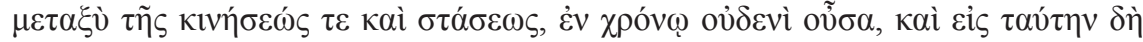

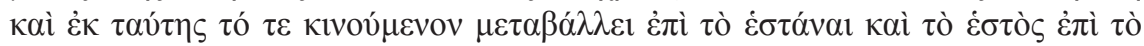

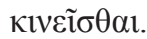

En efecto, 'instante' parece significar algo tal que a partir de ello se transita a cada uno [de los opuestos]. Pues ciertamente no se deja de reposar mientras se reposa, ni se deja de cambiar mientras se cambia; antes bien, el instante, esa naturaleza insospechada, se embosca entre el cambio y el reposo, no estando en ningún momento, y, hacia él y a partir de él, lo que muda pasa a estar quieto y lo quieto [pasa] a mudar.

Las investigaciones en la Academia llevaron a la interpretación polisémica de lo ente $^{58}$, pues Metaph. V 7 expone ya cuatro modos de entenderlo. Al igual que Platón, Aristóteles daba importancia al uso enunciativo de $\varepsilon \dot{\imath} \mu i^{59}$ y supeditaba la verdad de las proposiciones al sentido de lo ente en cada caso ${ }^{60}$. Sin embargo, su auténtica contribución fue precisar que lo ente se dice de tantas maneras cuantas clases de predicados hay, o sea, que cada determinación predicable representa un modo específico de ser. Por ejemplo, aunque la oración 'ese hombre es astuto' da a entender que un mismo referente 'es humano' y 'es astuto', las nociones de 'humanidad' y 'astucia' no caen bajo el mismo género de predicación ${ }^{61}$.

Aristóteles pudo imaginar la predicación como la acción de imputar cargos

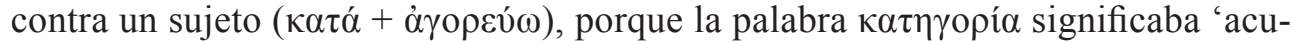
sación' en contextos jurídicos. Sin embargo, lo importante es que dichas 'imputaciones' caían bajo conceptos generales como 'entidad', 'cantidad', 'cualidad', 'relación', 'lugar', 'tiempo', 'estado/situación', ‘posesión/hábito', 'acción’ y ‘pasión', y eran designadas mediante expresiones que tematizaban interrogaciones

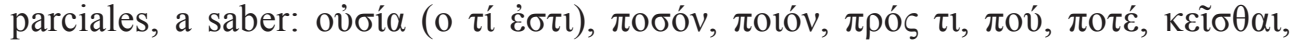

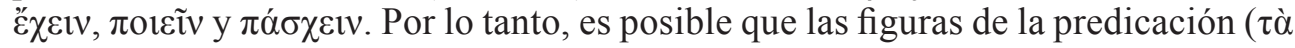

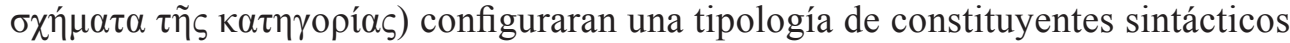

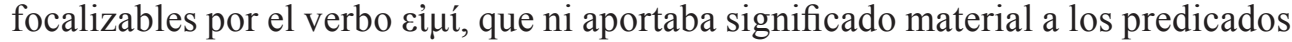
ni requería por sí mismo una determinada caracterización semántica del sujeto ( $v g$. agente, paciente, experimentante, beneficiario, posesor, etc.). Después de todo, Aristóteles conocía la neutralidad léxica de eíuí y la especificación categorial de

\footnotetext{
Cf. Simpl. in Phys. I 3 115.15-116.5.

Compárese Cra. 385b2-11 con Metaph. IV $71011 \mathrm{~b} 25-29$ y V 7 1017a31-35. Cf. Int. 16a13-18.

Véase Metaph. VI 4.

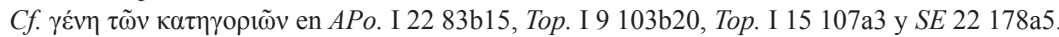




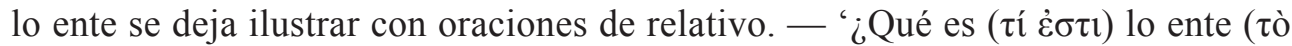
ǒv)'? - preguntaría A. - 'Es ( $\dot{\varepsilon} \sigma \tau \imath)$ un animal, que es (őv) mediano, que es dócil, que es mascota de otro animal, que está (őv) echado ahora en la sala, que está habituado a las visitas, que no está ( $\mu$ ò ơv) ladrando, que está siendo acariciado' - respondería $\mathrm{B}$.

Ahora bien, dada esa concepción categorial de lo ente, ¿cómo debemos entender las oraciones en que cíuí parece ser el único elemento del predicado? Cualquiera que sea nuestra lectura, resulta innecesario, y quizá inadecuado, traducir eĩvoı como 'existir' en tales casos. En primer lugar, o bien esas oraciones podrían omitir elementos predicativos ${ }^{62}$, o bien eíuí podría operar en ellas como los verbos transitivos que no modifican su naturaleza por construirse con o sin complementos ${ }^{63}$; recordemos que Aristóteles criticaba la vaguedad de enunciar lo ente de manera inespecífica $(\dot{\alpha} \pi \lambda \tilde{\omega} \varsigma)^{64}$. En segundo lugar, a diferencia de un verbo no copulativo y no auxiliar como 'existir', eíuí no era propiamente un verbo pleno y podía introducir cualquier predicado ${ }^{65}$. Moro (2017: 26-27) ilustra la naturaleza inespecífica de los verbos como eíuí con una analogía: así como el verbo to do no denota una acción particular, los verbos como eỉuí, por sí mismos, no expresan predicados específicos, ni siquiera el de 'existencia'. Es verdad que cífí parece denotar 'existencia' en diversas ocasiones ( $c f$. Cat. 12 14b9-23), pero ¿estamos seguros de no tomar por sujeto lo que es más bien un predicado en tales casos? Consideremos Metaph. IV 4 1006a18-32:

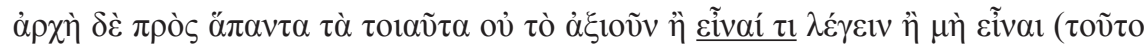

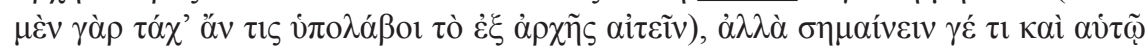

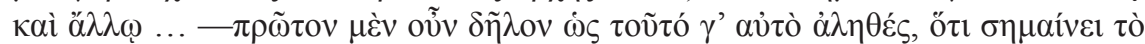

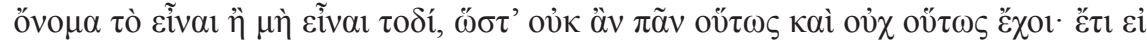

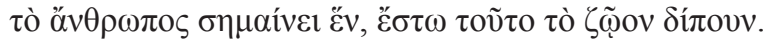

El punto de partida en todas esas situaciones no es solicitar que uno diga que algo es o no es (pues eso bien podría ser tomado como petición de principio), sino que significa algo para él mismo y para el otro ... Así pues, en primer lugar es evidente que esto es efectivamente verdadero en sí mismo: que la denominación significa 'ser o no ser tal cosa', de suerte que no todo podría hallarse así y no así; por lo demás, si 'hombre' significa una cosa, que sea 'animal bípedo'.

En la expresión subrayada, el pronombre $\tau$ representa una pieza léxica como 'trirreme', 'muro' u 'hombre' ( 1007b20-21). Pero ¿cómo debemos traducir cĩvaí $\tau \imath$ ? ¿Acaso el verbo denota 'existencia' en este caso? No; más bien presenta una determinación predicable. Aristóteles argumenta que, para probar la incondicionalidad del Principio de No-Contradicción, basta con rechazar ciertos rasgos semánticos, con restringir la intensión con que opera el adversario. Por tanto, lo que no hace falta es pedir al oponente que adjudique tales rasgos a una cosa. La expresión cĩvoí $\tau \imath$ omite la función sintáctica

\footnotetext{
Cf. Owen (1979: 181; 1986: 260-265; 2000: 418-428).

Cf. Brown (1994 y 2000).

Véase $S E 5$ 166b 37-167a6. Cf. Bäck (2000: 54).

Véase Int. 16b6-25 y Metaph. V 7 1017a23-24.
} 
correspondiente al sujeto, pues, tal como se afirma en Metaph. VII 17 1041a32-b9,

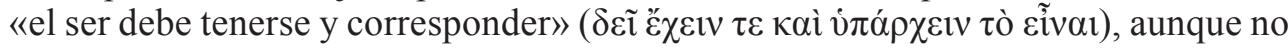
se mencione lo ‘imputado’ al considerar la determinación en sí misma:

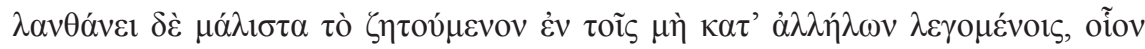

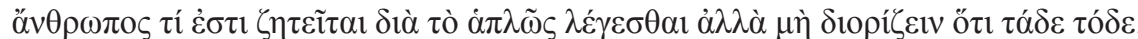

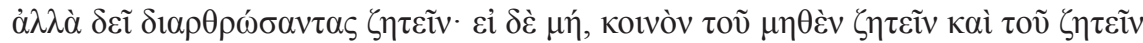

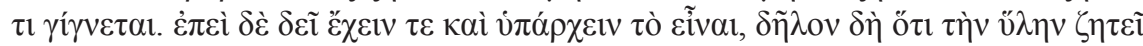

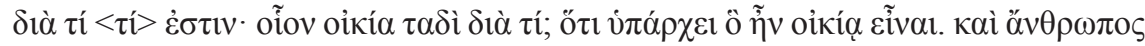

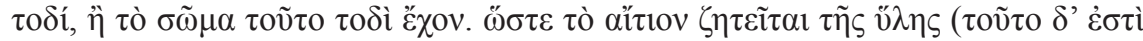

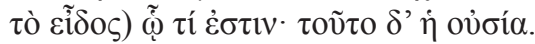

Oculto en extremo queda lo que se investiga en las cosas que no se dicen unas de otras: por ejemplo, se investiga qué es un hombre porque se dice [eso] sencillamente y sin especificar que tales cosas son tal cosa. Pero se debe investigar tras haber articulado [los dos términos de la relación predicativa]; si no, resulta que investigar algo es como no investigar nada. Pero, como el 'ser' debe tenerse y corresponder, es evidente que se investiga por qué la materia es algo. Por ejemplo: ¿Por qué tales cosas son una casa? Porque tiene lugar ‘qué era ser' para una casa. Y ¿[por qué] tales cosas, o sea, este cuerpo que tiene tales cosas es un hombre? Por lo tanto, se investiga la causa de que la materia sea algo (esto es, la forma específica); y esta es la entidad.

Así pues, en el ejemplo dado, un término como öv $\theta \rho \omega \pi$ o sería predicado ( $\tau$ ó $\delta \varepsilon$ ) de un sujeto material ( $\tau \alpha ́ \delta \varepsilon$ ). Y lo mismo pasaría en $A P o$. II $289 \mathrm{~b} 23-35$, donde se dis-

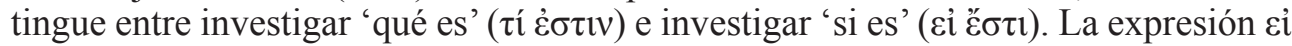
Ě $\sigma \tau \imath$ supone un sujeto y un predicado, de modo que inquiere, por ejemplo, 'si (algo)

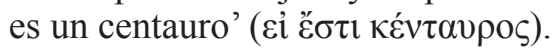

La inespecificidad semántica de cỉuí sostiene la concepción polisémica de lo ente,

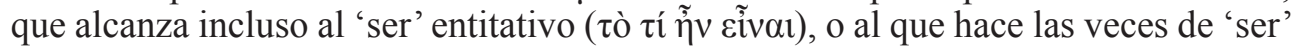
entitativo tratándose de cosas que no son entidades propiamente dichas. Por eso, Aristóteles afirmaba que «'ser' es 'vivir' para los vivientes» ${ }^{66}$ o que «'es' se dice de todas esas maneras: ya que es umbral lo que está tendido así, y 'ser' significa ese 'estar tendido así', y 'ser hielo' es 'haberse solidificado así' $\gg{ }^{67}$. Con todo, observemos a través de la polisemia de lo ente que Aristóteles enunciaba el 'ser' (Ẽ̃val) con infiniti-

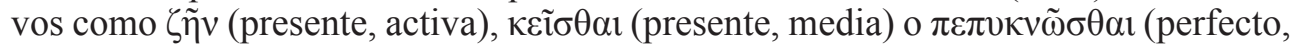
medio-pasiva), cuya morfología tiene implicaciones léxicas, aspectuales y diatésicas que permiten asociar el 'ser' de cada cosa con la dimensión dinámico-operativa de la metafísica aristotélica.

La distinción entre 'cambio' y ‘operación' en Metaph. IX 6 1048b18-35 remite a la oposición entre situaciones télicas y atélicas:

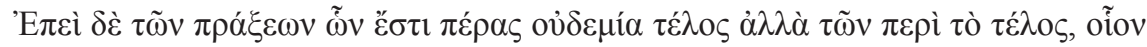

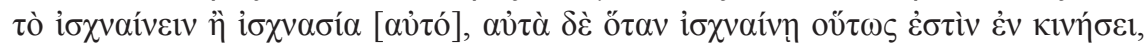

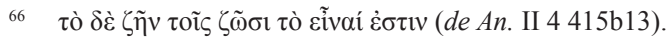

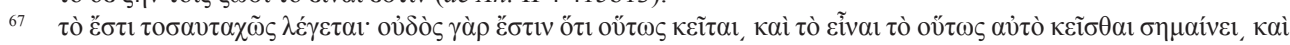

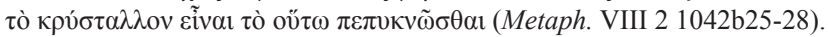




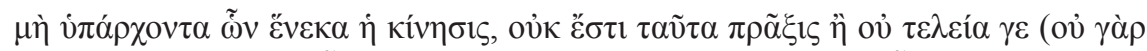

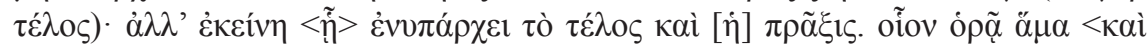

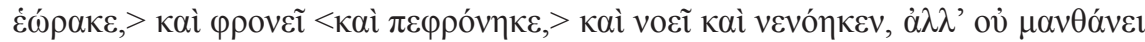

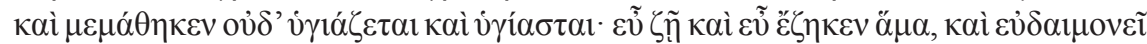

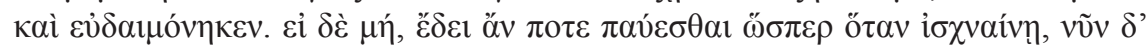

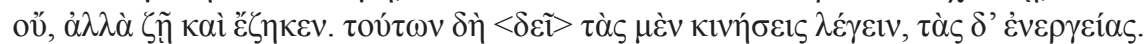

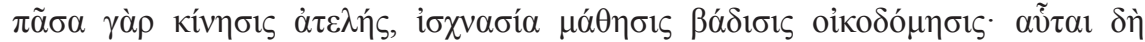

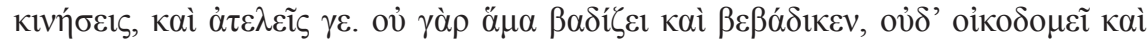

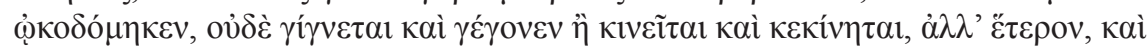

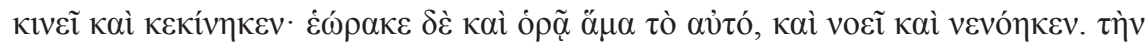

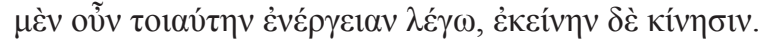

Puesto que ninguna de las acciones en que hay límite es una finalidad, sino que todas ellas [ocurren] por una finalidad - por ejemplo, la finalidad de adelgazar es la delgadez, y cuando estas [carnes] adelgazan, están cambiando de tal modo que no tiene lugar aquello para lo cual [ocurre] el cambio-, tales [acciones] no son [propiamente] una acción, o al menos no una completa (porque no son una finalidad): acción es más bien aquella en que se da la finalidad. Por ejemplo: al mismo tiempo uno ve y ha visto, piensa y ha pensado, entiende y ha entendido, pero no aprende y ha aprendido, ni sana y ha sanado. Uno vive bien y al mismo tiempo ha vivido bien, está feliz y ha estado feliz; de otro modo, debería detenerse en un momento dado como cuando adelgaza; pero en este caso no [es así], sino que vive y ha vivido. De estas [acciones], unas deben llamarse cambios, otras operaciones. En efecto, todos los cambios son incompletos: adelgazamiento, aprendizaje, avance, construcción; estos son cambios y son ciertamente incompletos. En efecto, uno no avanza y ha avanzado al mismo tiempo, ni construye [una casa] y [la] ha construido, ni deviene y ha devenido, ni cambia y ha cambiado, sino [que lo hace en un momento] distinto, así como mueve y ha movido. Pero lo mismo ha visto y ve al mismo tiempo, y entiende y ha entendido. Por lo tanto, llamo a esta [acción] 'operación', a aquella 'cambio'.

Aristóteles confronta la imperfectividad ('ve' $\approx$ 'está viendo') con la perfección aspectual ('ha visto' $\approx$ 'ha consumado el acto de ver') y nota que, a diferencia de los cambios (situaciones télicas), las operaciones (situaciones atélicas) pueden seguir ejecutándose a pesar de haberse ejecutado. No solo eso; tratándose de operaciones, el hecho de 'realizarse' puede coincidir temporalmente con el hecho de 'haberse realizado' porque las operaciones no son fases de un proceso (lineal o circular) y su realización no da paso a otro estado.

El concepto de ‘operación' era fundamental para la metafísica aristotélica, que, a partir de una teoría general de la entidad, especulaba sobre la entidad separada e inmutable ${ }^{68}$. Aristóteles estaba convencido de que la organización natural no se da por casualidad

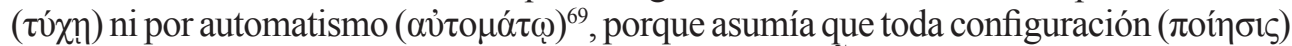

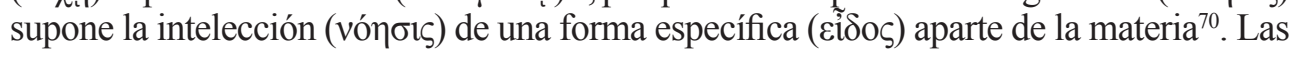

\footnotetext{
Cf. Metaph. VI 1.

Cf. Metaph. VII 7 1032b9-25 y XII 3 1070a4-9.

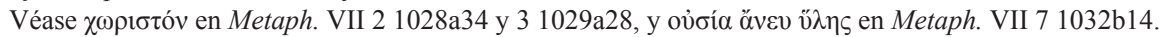


entidades compuestas de materia y forma mantenían su ser a través del cambio ${ }^{71}$, pero daban lugar a la potencialidad, porque llevaban a cabo acciones delimitadas bajo alguna categoría ${ }^{72}$ y admitían distinciones a través del tiempo ${ }^{73}$. Por eso, la finalidad de la naturaleza en su conjunto no podía residir en las entidades naturales, por más que la actividad esencial de todas ellas fuera una operación. Ninguna actividad infralunar o supralunar ${ }^{74}$, dependiente de la materia, podía mantener la coincidencia entre 'realizarse' y 'haberse realizado'. Solo un intelecto inmaterial, requerido por la configuración cósmica, podía permanecer en ese estado; de ahí que Aristóteles identificara la entidad separada e inmutable, garante de la organización natural, con la actividad libre de toda potencialidad, a saber, con la inteligencia en operación plena. Efectivamente, el concepto de 'operación' era fundamental para la metafísica aristotélica, así que cualquier interpretación satisfac-

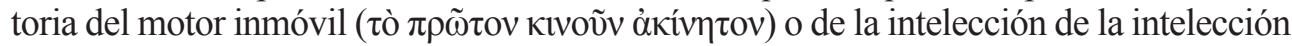

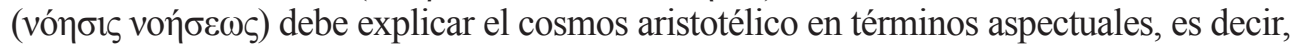
teniendo en cuenta la oposición entre acciones télicas y atélicas.

Para concluir, digamos que las ontologías de Parménides, Platón y Aristóteles proyectan los rasgos de eíú sobre una visión del mundo compartida por ellos en buena medida. Por un lado, dada la neutralidad de un verbo atributivo que ni

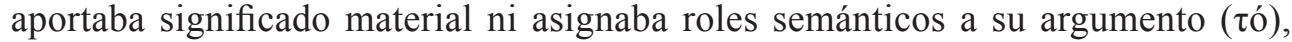
los filósofos griegos pudieron tipificar claramente los objetos de conocimiento, designación, manifestación, enunciación o pensamiento mediante distinciones categoriales de naturaleza léxica y morfosintáctica. Por otro lado, puesto que cỉuí expresaba duración e imperfectividad, es posible que los filósofos griegos atribuyeran estabilidad objetiva (őv) a dicha organización categorial, es decir, a los criterios con que aprehendían y determinaban la variedad temporal e intemporal

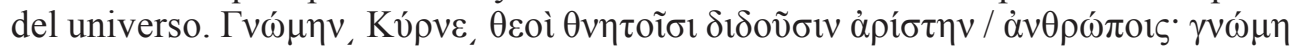
$\pi \varepsilon i ́ \rho \alpha \tau \alpha \pi \alpha \nu \tau o ̀ \varsigma ~ \varepsilon ้ \chi \varepsilon 1$ (Thgn. 1171-1172). Así pues, estas dos propiedades del verbo عỉuí deben orientar el estudio sistemático de los planteamientos más representativos de la metafísica griega, a saber: la doctrina parmenídea de lo ente y su relación con la investigación natural, la relación entre 'ser' y 'pensar', la visión dinámicooperativa del cosmos griego, la teoría de la participación, la teoría de las ideas, la

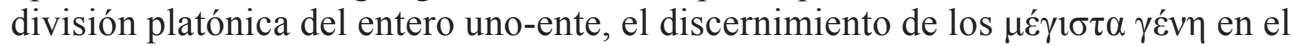
Sofista, la polisemia de lo ente según Aristóteles, la teoría de la ov̉oía y la referen-

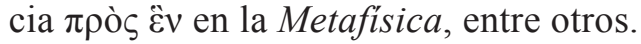

\section{Bibliografía}

Anderson, Gregory D.S. (2006), Auxiliary Verb Constructions, Oxford, Oxford University Press. Arche, Maria J. (2014), «The construction of viewpoint aspect: the imperfective revisited», Natural Language \& Linguistic Theory 32: 791-831. DOI: https://doi.org/10.1007/ s11049-013-9209-5.

Aristophanes. Clouds (ed. de Kenneth J. Dover), Oxford, Oxford University Press. 1970 (1968).

\footnotetext{
Cf. Metaph. IV 2 1003b5-19.

Véase Metaph. XI 12 y XII 2 y 10.

Las entidades admitían opuestos, pero no tenían opuestos en su línea (Cat. 3b24-32, 5 4a10-4b19).

Véase Metaph. XII 8 y 10 1075a16-25.
} 
Aristote. Du ciel (ed. de Paul Moraux), Paris, Les Belles Lettres, 1965.

Aristotelis categoriae et liber de interpretatione (ed. de Lorenzo Minio-Paluello), Oxford, Clarendon Press, 1966 (1949).

Aristotelis ethica Eudemia (ed. de Franz Susemihl), Amsterdam, Hakkert, 1967 (Leipzig, Teubner, 1884).

Aristotelis topica et sophistici elenchi (ed. de William David Ross), Oxford, Clarendon Press, 1970 (1958).

Aristotle. De anima (ed. de William David Ross), Oxford, Clarendon Press, 1967 (1961).

Aristotle's Prior and Posterior Analytics (ed. de William David Ross), Oxford, Clarendon Press, 1949.

Aristotle's Metaphysics, 2 vols. (ed. de William David Ross), Oxford, Clarendon Press, 1970 $\left(1953^{2}\right)$.

Bäck, Allan (2000), Aristotle's Theory of Predication, Leiden, Brill.

Back, Michael (1991), «Das Verhältnis von Aktionsarten und Tempus im Idg», Historische Sprachforschung 104: 279-302.

Benveniste, Émile (1966), «'Être’ et 'avoir' dans leurs fonctions linguistiques», en Problèmes de linguistique générale, Paris, Gallimard: 187-207.

Benvenuto, Maria Carmela \& Pompeo, Flavia (2015), «Verbal semantics in Ancient Greek possessive constructions with eînai», Journal of Greek Linguistics 15: 3-33. DOI: https:// doi.org/10.1163/15699846-01501004.

Bernabé Pajares, Alberto (2007) = Parménides, Poema (fragmentos y tradición textual), ed. y trad. de A. Bernabé Pajares; introd., notas y comentarios de J. Pérez de Tudela; epílogo de N. L. Cordero. Madrid: Istmo, 2007.

Bernabé Pajares, Alberto (2019), «Parménides: entre lingüística, literatura y filosofía», en A. Bernabé Pajares et al., Parmenide: tra linguistica, letteratura e filosofia, Baden-Baden, Academia Verlag: 49-118. DOI: https://doi.org/10.5771/9783896658081-1.

Bhat, D.N. Shankara (1994), The Adjectival Category: Criteria for Differentiation and Identification, Amsterdam-Philadelphia, John Benjamins.

Brown, Lesley (1994), «The verb "to be" in Greek philosophy: some remarks», en S. Everson (ed.), Language, Cambridge, Cambridge University Press: 212-236.

Brown, Lesley (2000), «Being in the Sophist: a syntactical enquiry», en G. Fine (ed.), Plato, Oxford, Oxford University Press: 457-480.

Buck, Carl Darling (1971), A Dictionary of Selected Synonyms in the Principal Indo-European Languages, Chicago-London, University of Chicago.

Cicero, Über das Fatum (ed. y trad. de Karl Bayer), München, Heimeran, $1976^{2}$.

Comrie, Bernard (19983), Aspect. An Introduction to the Study of Verbal Aspect and Related Problems, Cambridge, Cambridge University Press.

Cordero, Néstor Luis (2005), Siendo, se es. La tesis de Parménides, Buenos Aires, Biblos.

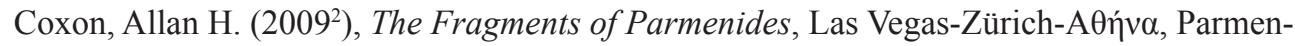
ides Publishing.

Cunliffe, Richard John (1963), A Lexicon of the Homeric Dialect, Norman (Oklahoma), Oklahoma University Press.

Demirdache, Hamida \& Uribe-Etxebarria, Myriam (2000), «The primitives of temporal relations», en R. Martin, D. Michaels y J. Uriagereka (eds.), Step by Step, Cambridge (MA) MIT Press: $157-186$.

Devine, Andrew M. \& Stephens, Laurence D. (1994), The Prosody of Greek Speech, New York-Oxford, Oxford University Press.

Diels, Hermann (2003²), Parmenides Lehrgedicht, Sankt Augustin, Akademia Verlag. 
Diels, Hermann \& Kranz, Walther $\left(1960^{\circ}\right)$, Die Fragmente der Vorsokratiker, Berlin, Weidmann.

Dik, Simon C. (1987), «Copula auxiliarization: how and why?», en M. Harris \& P. Ramat (eds.), Historical Development of Auxiliaries, Berlin-New York-Amsterdam. Mouton De Gruyter: 53-84.

Epictetus, The Discourses as Reported by Arrian, The Manual, and Fragments, vol. 1, (ed. y trad. de William Abbott Oldfather) London-Cambridge (MA), Harvard University Press, 1956 (1925).

Finkelberg, Aryeh (1988), «Parmenides: between material and logical monism», Archiv für Geschichte der Philosophie 70: 1-14.

Fränkel, Hermann (1930), «Parmenidesstudien», Nachrichten der Akademie der Wissenschaften zu Göttingen, Philologisch-Historische Klasse 19: 153-192.

Freeze, Ray (1992), «Existentials and other locatives», Language 68: 553-595.

Gaiser, Konrad (19983), Platons ungeschriebene Lehre. Studien zur systematischen und geschichtlichen Begründung der Wissenschaften in der Platonischen Schule, Stuttgart, Ernst Klett Verlag.

Gallop, David (1984) = Parmenides of Elea, Fragments. A Text and Translation with an Introduction by David Gallop, Toronto, University Press.

García Calvo, Agustín (2018) = Parménides, edición crítica, versión rítmica y paráfrasis de los fragmentos del poema por A. García Calvo; editadas con prolegómenos, comentario y texto de las fuentes y los testimonios indirectos por L.-A. Bredlow. Zamora, Lucina.

Gardella, Mariana (2014), «La metafísica megárica: unidad, identidad y monismo predicativo», Diánoia 59: 3-26. DOI: https://doi.org/10.21898/dia.v59i73.79.

Goclenius, Rodolphus (1613), Lexicon philosophicum quo tanquam clave philosophiae fores aperiuntur, Frankfurt am Main, Musculus.

Hazout, Ilan (2004), «The syntax of existential constructions», Linguistic Inquiry 35: 393430. DOI: https://doi.org/10.1162/0024389041402616.

Hegel, Georg Wilhelm Friedrich (1986), Werke. Band 3. Phänomenologie des Geistes (ed. de E. Moldenhauer), Frankfurt am Main, Suhrkamp.

Hengeveld, Kees (1992), Non-Verbal Predication: Theory, Typology, Diachrony, Berlin-New York, Mouton De Gruyter.

Hermann, Gottfried (1801), De emendanda ratione Graecae grammaticae, Pars Prima, Leipzig, Teubner.

Herodiani Technici reliquiae, 3 vols. (ed. de Augustus Lentz), Hildesheim, Olms, 1965 (Leipzig, Teubner, 1868).

Hérodote. Histoires, 9 vols. (ed. de Philippe-Ernest Legrand), Paris, Les Belles Lettres, 1932-1970.

Hesiod. Theogony (ed. de Martin L. West), Oxford, Oxford University Press, 1966.

Hölscher, Uvo (2014) = Parmenides, Vom Wesen des Seienden, ed. y trad. alemana de U. Hölscher; introd. y reedición de A. Reckermann, Hamburg, Felix Meiner.

Homeri Ilias (ed. de Martin L. West), Stuttgart-Leipzig, Teubner, 1998-2000.

Homeri Odyssea (ed. de Peter von der Mühll), Basel, Helbing \& Lichtenhahn, 1962.

Horrocks, Geoffrey $\left(2014^{2}\right)$, Greek. A History of the Language and its Speakers, Oxford, Wiley-Blackwell.

Jespersen, Otto (1924), The Philosophy of Grammar, London, Allen \& Unwin.

Kahn, Charles H. $\left(2003^{2}\right)$, The Verb 'Be' in Ancient Greek, Indianapolis, Hackett

Kirk, Geoffrey S., Raven, John E. \& Schofield, Malcolm $\left(2003^{2}\right)$, The Presocratic Philosophers. A Critical History with a Selection of Texts. Cambridge, Cambridge University Press. 
Koch, Peter (2012), «Location, existence, and possession: a constructional-typological exploration», Linguistics 50: 533-603. DOI: https://doi.org/10.1515/ling-2012-0018.

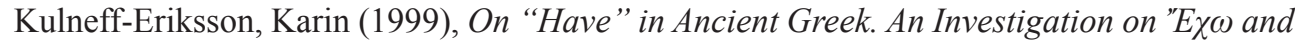
the Construction Eival with Dative as Expressions for "Have", Lund, Lund University Press.

Kurzová, Helena (1993), From Indo-European to Latin. The Evolution of Morphosyntactic Type, Amsterdam-Philadelphia, John Benjamins.

Lenci, Alessandro (1998), «The structure of predication», Synthese 114: 233-276. DOI: 10.1023/A:1005068021890

LSJM = Liddell, Henry George, Scott, Robert, Jones, Henry Stuart \& McKenzie, Roderick (19699), A Greek-English Lexicon. Oxford, University Press Press.

Lloyd, Antony C. (1967), «Athenian and Alexandrian Neoplatonism», en A. H. Armstrong (ed.), The Cambridge History of Later Greek and Early Medieval Philosophy, Cambridge, Cambridge University Press: 302-326.

Lloyd, Geoffrey E. R. (1987 [1966]), Polaridad y analogía. Dos tipos de argumentación en los albores del pensamiento griego, trad. de L. Vega, Madrid, Taurus.

Luthala, Anneli (2000), On the Origin of Syntactical Description in Stoic Logic, Münster, Nodus.

Lyons, John (1967), «A note on possessive, existential and locative sentences», Foundations of Language 3: 390-396.

Lyons, John (1968), Introduction to Theoretical Linguistics, Cambridge, Cambridge University Press.

Maienborn, Claudia (2003), Die logische Form von Kopula-Sätzen, Berlin, Akademie Verlag.

Mansfeld, Jaap \& Primavesi, Oliver $\left(2012^{3}\right)$, Die Vorsokratiker, Stuttgart, Reclam.

Meillet, Antoine (1906), «La phrase nominale en indo-européen», Memoires de la Societé de Linguistique de Paris 14: 1-26.

Mill, John Stuart (1981) = Robson, John M. (1981³), Collected Works of John Stuart Mill, vol. VII: A System of Logic, I-III $\left(1872^{8}\right)$, Toronto-London, University of Toronto PressRoutledge \& Kegan Paul.

Moro, Andrea (1997), The Raising of Predicates. Predicative Noun Phrases and the Theory of Clause Structure, Cambridge, Cambridge University Press.

Moro, Andrea (2017), A Brief History of the Verb To Be (trad. inglesa de B. McClellanBroussard) Cambridge (MA), MIT Press.

Mourelatos, Alexander P. D. (1978), «Events, processes, and states», Linguistics and Philosophy 2: 415-434. DOI: https://doi.org/10.1007/BF00149015.

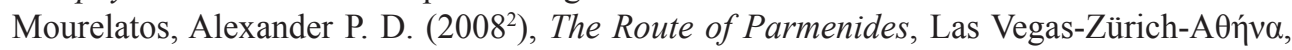
Parmenides Press.

Napoli, Maria (2006), Aspect and Actionality in Homeric Greek. A Contrastive Analysis. Milano, Franco Angeli.

Nehamas, Alexander (1981), «On Parmenides three ways of inquiry», Deukalion 33-34: 97-111.

NGLE = Real Academia Española y Asociación de Academias de la Lengua Española (2009), Nueva gramática de la lengua española. Morfología y sintaxis, 2 tt. Madrid, RAE.

O’Brien, Denis \& Frère, J. (1987) = Aubenque, Pierre (dir.), Études sur Parménide I. Le Poème de Parménide, Paris, Vrin.

Owen, Gwilym E. L. (1979), «Logic and metaphysics in some earlier works of Aristotle», en J. Barnes, M. Schofield \& R. Sorabji, Articles on Aristotle, vol 3. Metaphysics, London, Duckworth: 180-199. 
Owen, Gwilym E. L. (1986), «Aristotle on the snares of ontology», en M. Nussbaum, Science and Dialectic. Collected Papers in Greek Philosophy, London, Duckworth: 259-278.

Owen, Gwilym E. L. (2000), «Plato on not-being», en G. Fine (ed.), Plato, Oxford, Oxford University Press: 418-456.

Palmer, John (2009), Parmenides and Presocratic Philosophy, Oxford, Oxford University Press.

Platonis opera, 5 vols. (ed. de John Burnet), Oxford, Oxford University Press, 1967-1968 (1900).

Pokorny, Julius (1989), Indogermanisches etymologisches Wörterbuch, Band I, Bern-Stuttgart, Francke.

Porroche Ballesteros, Margarita (1988), Ser, estar y verbos de cambio, Madrid, Arco Libros.

Proclus, The Elements of Theology (ed. y trad. inglesa de Eric Robertson Dodds) Oxford, Oxford University Press, 1992.

Pustet, Regina (2003), Copulas. Universals in the Categorization of the Lexicon, Oxford, Oxford University Press.

Reinhardt, Karl (1977³ [1916]), Parmenides und die Geschichte der griechischen Philosophie, Frankfurt am Main, Klostermann.

Rijksbaron, Albert (2002), The Syntax and Semantics of the Verb in Classical Greek, Amsterdam, Brill.

Ringe, Donald $\left(2017^{2}\right)$, From Proto-Indo-European to Proto-Germanic, Oxford, Oxford University Press.

Rix, Helmut $\left(2001^{2}\right)$, Lexikon der indogermanischen Verben. Die Wurzeln und ihre Primärstammbildungen, Wiesbaden, Reichert.

Robins, Robert H. (19974), A Short History of Linguistics, London-New York, Routledge.

Russell, Bertrand (1920²), Introduction to Mathematical Philosophy, London-New York, Allen \& Unwin-Macmillan.

Russell, Bertrand (2000), History of Western Philosophy, London, Routledge.

Seneca, L. A., Epistulae morales ad Lucilium, Band I (ed. y trad. alemana de Gerhard Fink) Düsseldorf, Artemis \& Winkler, 2007.

Shields, Kenneth (1978), «Speculations concerning the I.E. root*es-», Archivum Linguisticum 9: 73-78.

Shields, Kenneth (1992), A History of Indo-European Verb Morphology, Amsterdam-Philadelphia, John Benjamins.

Shields, Kenneth (1997), «The origin of dialectal ablaut patterns of the present active indicative of IE *es- "to be"», Historische Sprachforschung 110: 176-180.

Simplicii in Aristotelis physicorum libros quattuor priores commentaria, (ed. de Hermann Diels) en Commentaria in Aristotelem Graeca, vol. IX, Berlin, G. Reimer 1882.

Smyth, Herbert Weyr (1920), A Greek Grammar for Colleges, New York, American Book Company.

Stassen, Leon (1997), Intransitive Predication, Oxford, Oxford University Press.

Szemerényi, Oswald (1987), «The origin of aspect in the Indo-European languages», Glotta 65: 1-18.

Szemerényi, Oswald (19904), Einführung in die vergleichende Sprachwissenschaft, Darmstadt, Wissenschaftliche Buchgesellschaft.

Tapia Zúñiga, Pedro C. (2013) = Homero, Odisea (versión rítmica de Pedro C. Tapia Zúñiga), México, UNAM.

Tarán, Leonardo (1965), Parmenides. A Text with Translation, Commentary, and Critical Essays, Princeton, Princeton University Press. 
Thucydidis historiae 2 vols. (ed. de Henry Stuart Jones y John Enoch Powell), Oxford, Oxford University Press, 1967-1970 (1942).

Teognis de Mégara = Theognis, Mimnermos, Phokylides, Frühe griechische Elegien (trad. introd. y comentario de Dirk Uwe Hansen). Darmstadt, Wissenschaftliche Buchgesellschaft, 2005.

Untersteiner, Mario (1958), Parmenide. Testimonianze e Frammenti, Firenze, La Nuova Italia.

Vendler, Zeno (1967), «Verbs and times», en Linguistics in Philosophy, Ithaca (NY), Cornell University Press: 97-121.

Watkins, Calvert $\left(2000^{2}\right)$, The American Heritage Dictionary of Indo-European Roots, Boston-New York, Houghton Mifflin.

Wedin, Michael V. (2011), «Parmenides' three ways and the failure of the Ionian interpretation», Oxford Studies in Ancient Philosophy 41: 1-65.

Wedin, Michael V. (2014), Parmenides' Grand Deduction. A Logical Reconstruction of the Way of Truth, Oxford, Oxford University Press.

Wittgenstein, Ludwig (2018), Tractatus logico-philosophicus - Logisch-philosophische Abhandlung (37 ${ }^{\mathrm{a}}$ reimp. [1963]), Frankfurt am Main, Suhrkamp.

Woodbury, Leonard (1958), «Parmenides on Names», Harvard Studies in Classical Philology 63: 145-160.

Xenophontis opera omnia, vol. 3 (ed. de Edgar C. Marchant) Oxford, Oxford University Press, 1961 (1904). 